\title{
Intraspecific diversity observed in the wild tomato species Solanum chilense in initial immune responses towards a glucan elicitor
}

Parvinderdeep S. Kahlon ${ }^{1}$, Andrea Förner ${ }^{1}$, Michael Muser ${ }^{1}$, Mhaned Oubounyt ${ }^{2}$, Michael

Gigl $^{3}$, Richard Hammerl ${ }^{3}$, Jan Baumbach ${ }^{2,4}$, Ralph Hückelhoven ${ }^{1}$, Corinna Dawid ${ }^{3}$ and Remco Stam $^{1 *}$

Running title: diversity in initial immune responses in natural populations

${ }^{1}$ Chair of Phytopathology, TUM School of Life Sciences, Technical University of Munich, Emil-Ramann-Str. 2, 85354, Freising, Germany

${ }^{2}$ Chair of Computational Systems Biology, University of Hamburg, Notkestrasse 9, 22607, Hamburg, Germany

${ }^{3}$ Chair of Food Chemistry and Molecular Sensory Science, TUM School of Life Sciences, Technical University of Munich, Lise-Meitner-Str. 34, 85354 Freising, Germany

${ }^{4}$ Computational BioMedicine lab, Institute of Mathematics and Computer Science, University of Southern Denmark, Campusvej 55, Odense, Denmark

*Author for correspondence: Remco Stam, Chair of Phytopathology, TUM School of Life Sciences, Technical University of Munich, Emil-Ramann-Str. 2, 85354, Freising, Germany, Email: stam@wzw.tum.de

Keywords: initial immune responses, phytohormones, natural populations, laminarin, diversity

\begin{abstract}
Natural plant populations are highly polymorphic and often show intraspecific quantitative, variation in resistance properties against pathogens. The activation of the underlying defence responses can depend on the perception of conserved pathogen-associated molecular patterns (PAMPs). To dissect and understand such variation, we evaluated the diversity of responses induced by laminarin (representing a general glucan elicitor of plant immune responses) in the wild tomato species Solanum chilense. We confirm considerable overlap of the plant's global transcriptional responses to laminarin and to the oomycete pathogen Phytophthora infestans. We further measured key components of basal defence responses such as reactive oxygen species (ROS) production and levels of diverse phytohormones and their derivatives upon
\end{abstract}


elicitation with laminarin in 83 plants originating from nine natural populations of $S$. chilense from distinct geographic origin. We found high diversity in these components at basal and elicitor-induced levels. We generated generalised linear mixed models (GLMMs) with these components to explain the observed resistance phenotype against $P$. infestans in the plants and found that additive effects of multiple components best explain resistance at the species level. For individual components, we observed the strongest positive correlation between the resistance phenotype and ethylene (ET) production upon laminarin elicitation. The strength of this correlation differed between individual populations. Chemical inhibition of ET production in individuals from a population, in which ET production was associated with resistance, provoked more severe disease symptoms. Our findings reveal high diversity in the strength of induced defence responses within a species and in the basal levels of stress-related phytohormones. We show the involvement of multiple components with a quantitatively different contribution of individual components to resistance in geographically separated populations of $S$. chilense against $P$. infestans.

\section{Introduction}

Plant defence responses against pathogens in natural populations are often polymorphic (Kahlon and Stam, 2021a). Depending on the host-pathogen system under study, resistance can be obtained either through a product of major resistance genes or as a product of polygenic defence mechanisms against the pathogen, which are often considered as basal defence. Major gene-mediated resistance is observed as pathogen genotype dependent and resistance is often obtained in a pathogen race-specific manner. Genes encoding nucleotide-binding domain leucine-rich repeat-containing proteins (NLR) are one example of major resistance genes. NLR genes have been studied in natural plant populations and are reported to be diverse at the genetic level (Stam et al., 2019a, Van de Weyer et al., 2019; Witek et al., 2021). Similarly, members of the receptor-like proteins (RLPs) family show intraspecific variation in the presence-absence of defence responses or variability in expression patterns of these genes (Van der Hoorn et al., 2001; Kruijt et al., 2005; Kahlon et al., 2020, Steidele and Stam, 2020). In many cases, major gene mediated resistance is complete. By contrast, basal resistance is often quantitative and pathogen race-nonspecific. This might partially be explained by its polygenic nature, and because underlying defence reactions can be activated upon exposure to general elicitors or conserved pathogen-associated molecular patterns (PAMPs). Flagellin peptides (flg22, flgII28) and chitin have been the dominant PAMPs for studies on resistance mechanisms in plants 
against pathogens from bacterial and fungal lineages respectively. Many additional PAMPs have been identified e.g.VmE02 homologs, produced by various fungi and oomycetes, can trigger immunity response in $N$. benthamiana (Nie et al., 2018) and peptide elicitor fractions from several Fusarium spp. activate early defence mechanisms in Arabidopsis thaliana (Coleman et al., 2021). One other example is laminarin, which is perceived in different plant species like Nicotiana tabacum (Klarzynski et al., 2000; Ménard et al., 2004), Grapevine, Vitis vinifera (Aziz et al., 2003), A. thaliana (Ménard et al., 2004), tea, Camellia sinensis (Xin et al., 2019), Nicotiana benthamiana, Hordeum vulgare, Brachypodium distachyon (Wanke et al., 2020) and Olive, Olea europaea (Tziros et al., 2021). Laminarin is considered to resemble components of oomycete cell walls (Aronson et al., 1967) and may induce defence responses similar to those provoked by elicitors from the oomycete lineage. The defence mechanisms activated upon recognizing these elicitors are very complex at the genetic level. Accordingly, in a diverse panel of wild and domesticated tomatoes basal quantitative resistance against the generalist fungal pathogen Botrytis cinerea has been reported to be dependent on the interaction of multiple loci among both host and pathogen (Soltis et al., 2019).

At the molecular level, diversity in basal defence responses against the bacterial pathogen Pseudomonas syringae pv. tomato (Pst) DC3000 has been shown by Velásquez et al. (2017) in different accessions of A. thaliana. The authors found effective defence responses via different mechanisms in 14 resistant accessions of the host out of 1041 screened. Resistance was shown to be mediated by an increased level of the phytohormone salicylic acid (SA) in three accessions, by a plant surface-based mechanism in two accessions, by an effector triggered immunity-like mechanism in six accessions and by unknown mechanisms in three accessions. In some plant-pathogen interactions it has been shown that basal immune responses at the molecular level can be quantified in plants by measuring ROS production upon interaction with the pathogen or pathogen-specific molecules (Torres et al., 2006). The finetuning in the production of ROS is one important cue toward activating resistance mechanisms which lead to the production of various phytohormones or activation of downstream defence regulators (Ramirez-Prado et al., 2018). Roberts et al. (2019) showed the amount of ROS production varied when different tomato populations were treated with flagellin peptides (flg22, flgII-28). Besides the production of ROS, phytohormones present or induced in the plant can greatly influence the resistance outcome. SA is a well-studied regulator of several defence response pathways in A. thaliana (e.g. Liu et al., 2020a). A higher level of SA is shown to be important in activating defence response in tomato leaves against $P$. infestans (Jeun $e t$ al., 2000). Genes involved in ET and SA pathways have turned out to be important in $N$. 
benthiamana after infection with $P$. infestans (Takemoto et al., 2018). A study on potato shows that upon infection with $P$. infestans large set of genes are upregulated at multiple time points post-inoculation. These included key marker genes involved in the jasmonic acid (JA) acid signalling pathway and genes involved in primary and secondary metabolite pathways (Tian et $a l ., 2006)$. In cultivated tomato the negative role of abscisic acid (ABA) in resistance against Botrytis cinerea is regulated by repressing SA signalling (Audenaert et al., 2002). Whereas resistance against Alternaria solani in cultivated tomato is enhanced upon exogenous ABA application through defence-related gene activation and defense-related enzymatic activity of phenylalanine ammonia-lyase (PAL), polyphenol oxidase (POD) and peroxidase (PPO) (Song et al., 2011). Exogenous application of indoleacetic acid (IAA) in the soil resulted in Fusarium oxysporum lycopersici disease suppression in tomato plants (Sharaf and Farang, 2004).

In this study, we use a wild tomato species Solanum chilense to elucidate molecular cues behind the diversity in resistance against the oomycete, P. infestans (Stam et al., 2017; Kahlon et al., 2021). Both, quantitative and qualitative resistance against $P$. infestans has been reported in different wild species across the Solanum genus. Major resistance genes have long been exploited to deliver resistance to previously susceptible domesticated crops. One of the first examples was the study from Black et al., (1953) reporting four major genes delivering resistance in potato seedlings bred from the wild species Solanum demissum. Such major genemediated resistance observed in wild relatives of Solanum species has been instrumental for various plant breeding programs in conferring resistance against $P$. infestans (Hein et al., 2009). In addition to qualitative resistance, quantitative resistance has been also explored in the context of favorable outcomes in potato resistance breeding (Ewing et al., 2000; Bradshaw et al., 2004). In the case of the wild tomato Solanum pennellii resistance to P. infestans was dependent on quantitative trait loci and varying levels of resistance were observed among individuals in the offspring of crosses of cultivated tomato and S. pennellii (Smart et al., 2007). S. chilense is a suitable organism to study the variation of molecular responses associated with basal defence mechanisms. Populations of $S$. chilense are geographically structured in four distinct groups based on genomic studies (Böndel et al., 2015; Stam et al., 2019a). The two southern groups are recent expansions of the species, are genetically more divergent and might be developing into new subspecies (Raduski and Igic, 2021). Thus the system provides a strong genetic structure. Previously we found variation in defence responses against the fungal leaf pathogen Cladosporium fulvum (syn. Fulvia fulva, Passalora fulva), with complete loss of pathogenic protein recognition in plants from the southern groups (Kahlon et al., 2020). Furthermore, we showed clear quantitative differences in resistance against three common 
filamentous pathogens (Stam et al., 2017) in different S. chilense populations. In a recent report (Kahlon et al., 2021) we showed that such differences in quantitative resistance in geographically distinct locations of $S$. chilense against $P$. infestans are predominantly driven by the host genotype.

Here, we aim to dissect the various possible immune responses in S. chilense populations. We specifically investigate the basal defence responses in $S$. chilense upon challenge with the nonspecific elicitor laminarin. We confirm that laminarin elicits a subset of defence responses triggered by $P$. infestans, we report high diversity in several key regulators of basal immune responses in S. chilense within and between populations of the species, and we assess their individual and joint effect on the interaction outcome.

\section{Materials and methods}

\section{Plants material used and maintained}

We used 83 plants of $S$. chilense originating from nine populations (accessions) (8-10 plants each): LA1958, LA1963, LA2747, LA2932, LA3111, LA3786, LA4107, LA4117A and LA4330. The seeds of these populations were procured from the C. M. Rick Tomato Genetics Resource Center of the University of California, Davis (TGRC UC-Davis, http://tgrc.ucdavis.edu/). Plants were sown and maintained in controlled greenhouse conditions (16h light and $24^{\circ} \mathrm{C}$ temperature at daytime and $18-20^{\circ} \mathrm{C}$ at night). Each plant used in this study was at least a year old. Plants were maintained throughout the experiments by cutting them biweekly. Each population used in this study represents one of four geographical locations of the species habitat and were originally collected during different years from wild populations. The plants are propagated by TGRC to maintain the maximum genetic diversity (see also Böndel et al., 2015). Each individual plant within a population is genetically unique.

\section{Evaluation of laminarin potential to activate initial immune responses similar to $P$. infestans using 3' RNAseq}

We selected the central population LA3111 to evaluate differentially expressed genes in the transcriptome upon challenging with $P$. infestans Pi100 (3000 sporongia/ml) and laminarin (1 $\mathrm{mg} / \mathrm{ml}$, Sigma-Aldrich) treatment (using spray inoculation). We use LA3111 population because the reference genome of $S$. chilense was generated from an individual from this population (Stam et al., 2019b). To measure the general defence responses in the population, the experiment was done on nine plants and all plants were pooled per treatment for the RNA 
extraction. Detached leaves were kept upside down in plastic boxes containing wet tissue beds and treated with water, laminarin or $P$. infestans. The boxes were kept at $18-20^{\circ} \mathrm{C}$ for 3 hours and samples were taken and snap-frozen in liquid nitrogen. RNA was isolated using Qiagen ${ }^{\circledR}$ RNeasy plant mini kit according to the instruction manual. Each treatment consisted of pooled samples of nine plants and four technical replicates of each treatment.

3'RNA libraries were prepared according to the manufacturer's protocol using the QuantSeq 3'mRNA-Seq Library Prep Kit (Lexogen, Vienna, Austria). Sequencing was performed on a HiSeq2500 (Illumina, San Diego, CA, USA) with single-end 100bp reads using Rapid SBS v2 chemistry. The raw sequencing reads in FastQ format were trimmed to remove adapter sequences using Trimmomatic v0.39 (Bolger et al., 2014). The reads were quality filtered and trimmed using the following settings: LEADING:3, SLIDINGWINDOW:4:15, MINLEN:40. HISAT2 (Kim et al., 2015) was used to align sequencing reads to a reference genome (Stam et al., 2019b). After alignment, featureCounts (Liao et al., 2014) was used to identify the number of reads that mapped to genes. For feature Counts, all entries tagged as 'gene' were extracted from the gff annotation files and by adjusting the gene_id and transcript_id identifiers, this gene list was converted into a gtf annotation file. The downstream region of every gene was extended by $1 \mathrm{~kb}$ (the extension stops when it hits the next gene start site). FeatureCounts was modified to search for the tag 'gene' instead of the default 'exon' tag.

Differential gene expression analysis was carried out using the R package DESeq2 (Love et $a l ., 2014)$. DESeq2 uses the output of featureCounts to estimate the fold change in gene expression between different treatment groups. Default parameters from the DESeq2 package were applied and differentially expressed genes (DEGs) showing adjusted $p$-value $<0.05$ were considered significant.

Gene Ontology (GO) enrichment analysis was based on previously annotated ontologies (Stam et al., 2019b). GO terms were selected for all candidate genes. The Background frequency of each GO term is the number of genes annotated to this GO term in all genes, while sample frequency is the number of genes annotated to that GO term in the list of DEGs in this sample. For the manual inspection of the functions of the differentially expressed overlapping gene candidates in laminarin and $P$. infestans treated samples, we performed a BLAST search, extracted gene names and functional annotation from the best hits and if needed, performed a literature search for papers that described the functions of the described gene candidates.

\section{Gene expression analysis of the key indicators of phytohormones pathways via qPCR}


To independently evaluate phytohormone regulation in response to laminarin $(1 \mathrm{mg} / \mathrm{ml})$ elicitation we tested the expression level of key indicators of three well-known defence phytohormones 1-aminocyclopropane-1-carboxylic acid synthases 2, ACS2 from the ET pathway (Gravino et al., 2015), isochorismate synthase, ICS (Di et al., 2017) and phenylalanine ammonia-lyase, PAL (Peng et al., 2004) from the SA pathway and lipoxygenase D, LOXD; (Heitz et al., 1997) from the JA pathway, in individual plant leaf discs of S. chilense upon treatment with laminarin and compared it to mock-treated (water) leaf discs. S. chilense reference names of the genes are provided in Table $\mathrm{S} 1$.

Leaf discs of the plant LA1963-02 (chosen due to its high resistance observed in Kahlon et al., 2021) were treated with laminarin and MilliQ- $\mathrm{H}_{2} \mathrm{O}$ treated leaf discs served as control. Experiments were performed on three different dates in three independent replicates each. Samples were treated for 1.5 hours, snap-frozen in liquid nitrogen and ground to a fine powder with a mortar and pestle. RNA was extracted using the Qiagen ${ }^{\circledR}$ RNeasy plant mini kit according to the instruction manual. cDNA synthesis was performed using a Qiagen QunatiTect ${ }^{\circledR}$ reverse transcriptase kit according to the instruction manual. Quantitative PCR (qPCR) was performed on the synthesised cDNA using Takyon ${ }^{\mathrm{TM}}$ Low ROX SYBR ${ }^{\circledR}$ master mix ddTTP blue (Eurogentec Liège, Belgium). qPCR was performed in three technical replicates and a non-template control was included. Primer pairs for each tested gene are indicated in Table S1, TIP-41 (Fisher et al., 2013; Nosenko et al., 2016) was used as a housekeeping gene for normalization and primer efficiency was performed for all the primer pairs and are shown in Table S1. The PCR reaction comprised of $10 \mu 1$ SYBR Green-ROX Mix, $0.3 \mu \mathrm{M}$ of forward primer and $0.3 \mu \mathrm{M}$ of reverse primer, $3 \mu \mathrm{l}$ of cDNA and volume was adjusted to $20 \mu \mathrm{l}$ with MilliQ- $\mathrm{H}_{2} \mathrm{O}$. The thermal cycling profile was set to a hot start at $95^{\circ} \mathrm{C}$ for 3 minutes, followed by 40 cycles of amplification $\left(95^{\circ} \mathrm{C}\right.$ for 30 seconds, $60^{\circ} \mathrm{C}$ for 30 seconds, $72^{\circ} \mathrm{C}$ for 1 minute), 1 cycle melting $\left(95^{\circ} \mathrm{C}\right.$ for 30 seconds, $65^{\circ} \mathrm{C}$ for 30 seconds, $95^{\circ} \mathrm{C}$ for 30 seconds), and in the end 1 cycle at $72^{\circ} \mathrm{C}$ for 10 minutes. Melting curve temperatures were recorded at the end of the cycle for quality control. Data were evaluated with the software Agilent Aria MX 1.7 and relative gene expression was calculated based on the Livak and Schmittgen method (2001).

\section{ROS production measurement}

To measure ROS production upon elicitation with laminarin, we performed a 96-well plate assay based on chemiluminescence as described by Kahlon and Stam (2021b). Leaf discs from leaves of mature plants were made with a biopsy punch $(4 \mathrm{~mm}$, KAI Medical Solingen, 
Germany) and incubated in white 96-well flat-bottom plate overnight in $200 \mu 1$ of $20 \mathrm{mM}$ MOPS $(\mathrm{pH} 7.5)$ at room temperature. The next day buffer was removed and wells were supplemented with $75 \mu \mathrm{l} \mathrm{HRP} \operatorname{mix}(10 \mu \mathrm{M}$ horseradish peroxidase (HRP) and 10 $\mu \mathrm{M}$ L012). A baseline reading was performed for the initial 10 minutes using a Luminoskan Ascent (Thermo Scientific) and then laminarin (1mg/ml final concentration) dissolved in MOPS was added to the plate at 4 wells/plant. For each population, the assay was performed on three different dates with four technical replicates each for treatment and mock (MOPS) per date. In addition, we performed ROS production measurements with flg22 at a final concentration of $500 \mathrm{nM}$ in population LA4330 (7 plants) to compare it with specificity of laminarin in ROS production. Normalization of data was performed by first averaging over the initial 6-10 minutes baseline reading, followed by normalization to the mock treatment for the treated leaf discs.

\section{Phytohormone measurements: ET measurements}

Leaf discs were obtained with a $4 \mathrm{~mm}$ biopsy punch and incubated overnight in Petri dishes containing milliQ- $\mathrm{H}_{2} \mathrm{O}$ at room temperature. Following overnight incubation, three leaf discs were added to glass vials $(5 \mathrm{ml})$ containing $300 \mu \mathrm{l}$ of milliQ- $\mathrm{H}_{2} \mathrm{O}$. Laminarin was added in a final concentration of $1 \mathrm{mg} / \mathrm{ml}$ to 3 glass vials (samples) containing three leaf discs of one plant and milliQ- $\mathrm{H}_{2} \mathrm{O}$ in three separate glass vials containing leaf discs for same plant served as a negative control. Upon addition of elicitor or water, the glass vials were sealed with septa (Carl Roth $\mathrm{GmbH}$ ). Samples were incubated for three hours at a shaker at 20-50 rpm (Heidolph Polymax 2040). 3 hours post-incubation, $1 \mathrm{ml}$ of air was retrieved from each samples with a syringe through the rubber cap and injected into a Varian 3300 gas chromatography machine containing $\mathrm{AlO}_{3}$ column with length $1 \mathrm{~m}$ and $225^{\circ} \mathrm{C}$ detector temperature and $80^{\circ} \mathrm{C}$ column and injector temperature. The gases used for the separation of ET from the sample were $\mathrm{H}_{2}, \mathrm{~N}_{2}$ and $\mathrm{O}_{2}$ at $0.5 \mathrm{MPa}$ each. The amount of ET was calculated based on the standard calculation as developed by Von Kruedener et al. (1994) using the area under the curve (AUC). In total, we measured up to nine samples per plant on three different dates, each date containing up to three samples.

\section{Phytohormone and their derivatives measurements: Measurement of SA, JA, ABA, IAA, phaseic acid (PA) and dihydrophaseic acid (DPA):}

Samples for measurements of these six compounds were also prepared based on the leaf disc treatment method. 150-200 leaf discs were made per plant using a 4mm diameter biopsy punch 
and incubated overnight in Petri dishes containing milliQ- $\mathrm{H}_{2} 0$. The next day for each plant a 6-well plate filled with milliQ- $\mathrm{H}_{2} \mathrm{O}$ was prepared for elicitation containing 25-30 leaf discs per well. Three wells were elicited with laminarin $(1 \mathrm{mg} / \mathrm{ml})$ and in the remaining three wells milliQ- $\mathrm{H}_{2} \mathrm{O}$ was added as a control. The plates were incubated for three hours at a shaker at 20-50 rpm. Following the treatments, the leaf discs were transferred to $2 \mathrm{ml}$ Eppendorf tubes and residual water was pipetted out before snap-freezing the samples in liquid nitrogen.

Fine powder from the plant material was obtained after grinding the frozen leaf discs with mortar and pestle in liquid nitrogen. The samples were then processed for extraction of the phytohormones and their derivatives as described by Chaudhary et al. (2020), with minor modifications. 50-200mg ground material was transferred to a $2 \mathrm{ml}$ bead beater tube (CKMix2ml, Bertin Technologies, Montigny-le-Bretonneux, France). $20 \mu 1$ of internal standard solution containing indoleacetic acid-d2 (Sigma Aldrich, Steinheim, Germany) $(2.5 \mu \mathrm{g} / \mathrm{ml})$, salicylic acid-d4 (Olchemim, Olomouc, Czech Republic) $(2.5 \mu \mathrm{g} / \mathrm{ml}),(+)$ cis, trans-abscisic acid-d6 (Sigma Aldrich, Steinheim, Germany) $(2.5 \mu \mathrm{g} / \mathrm{ml})$, and (-) trans-jasmonic acid-d5 $(25 \mu \mathrm{g} / \mathrm{ml})$ (Santa Cruz, Dallas, TX, USA) were dissolved in acetonitrile and added to the samples and incubated for 30 minutes at room temperature. Following that $1 \mathrm{ml}$ of ice-cold ethyl acetate (Art. 864, Merck, Darmstadt, Germany) was added to the samples and stored overnight at $20^{\circ} \mathrm{C}$. The next day samples were shaken for 3 X20 seconds using the bead beater (Precellys Homogenizer, Bertin Technologies, Montigny-le-Bretonneux, France) at 6000rpm with 40 seconds breaks in-between. The material was then filtered with a $0.45 \mu \mathrm{m}$ pore size filter (Sartorius, Darmstadt, Germany) using a Minisart ${ }^{\circledR}$ syringe. The filtrate was transferred to $2 \mathrm{ml}$ tubes and vacuum dried. Then samples were reconstituted in $70 \mu 1$ of acetonitrile and sonicated for 3 minutes. $2 \mu 1$ of the sample from the HPLC tubes (glass vials) were injected into the LCMS/MS system. The MS method used measured positive and negative ionization mode within one run (polarity switching). Negative ions were detected at an ion spray voltage of $-4500 \mathrm{~V}$ (ESI-) using ion source parameters: curtain gas $(35 \mathrm{psi})$, temperature $\left(550^{\circ} \mathrm{C}\right)$, gas $1(55 \mathrm{psi})$, gas 2 (65 psi), collision activated dissociation $(-3 \mathrm{~V})$, and entrance potential $(-10 \mathrm{~V})$. Positive ions were detected at an ion spray voltage at $4500 \mathrm{~V}$ (ESI+) using ion source parameters: curtain gas $(35 \mathrm{psi})$, temperature $\left(550^{\circ} \mathrm{C}\right)$, gas 1 (55 psi), gas $2(65 \mathrm{psi})$, collision activated dissociation $(-3 \mathrm{~V})$ and entrance potential $(10 \mathrm{~V})$ and $40^{\circ} \mathrm{C}$ column oven temperature was at a QTRAP 6500+ mass spectrometer (Sciex, Darmstadt, Germany). MS/MS fragmentation was obtained and samples were separated by ExionLC UHPLC (Shimadzu Europa GmbH, Duisburg, Germany) using $100 \times 2.1 \mathrm{~mm} 2,100 \AA$, $1.7 \mu \mathrm{m}$, Kinetex F5 column (Phenomenex, Aschaffenburg, Germany). Solvent used for separation were (A) $0.1 \%$ formic acid in water 
$(\mathrm{v} / \mathrm{v})$ and (B) $0.1 \%$ formic acid in acetonitrile (v/v) with a flow rate of $0.4 \mathrm{ml} / \mathrm{minute}$. Chromatographic separation was performed with the gradient of $0 \% \mathrm{~B}$ for 2 minutes, increased in 1 minute to $30 \% \mathrm{~B}$ and in 12 minutes to $30 \% \mathrm{~B}$, increased in 0.5 minute to $100 \% \mathrm{~B}$, held 2 minutes isocratically at $100 \% \mathrm{~B}$, decreased in 0.5 minute to $0 \% \mathrm{~B}$, and held 3 minutes at $0 \%$ B. Phytohormone quantification was performed based on comparison with standard curves prepared with purified hormones and using AUC. The final concentrations were obtained in nanograms of hormone per gram of fresh weight of the sample.

\section{Statistical analysis of the data, Pearson's correlation and linear mixed models for resistance phenotype with components of basal immunity and stress-related phytohormones}

All the data analyses were performed in the R software (version 3.4.4, R core Team, 2020). ANOVA was performed with the function aov(), and post hoc Tukey tests with the function TukeyHSD () , from the package $\{$ stats $\}$. When the $p$-value was lower than 0.05 it was considered significant. Pearson's correlation was performed using the function cor(). GLMMs were generated to evaluate the effect of measured immunity components on infection frequency (IF) using glmer() from the package $\{$ lme4 $\}$ (Bartes et al., 2015). The analyses were done for the 83 plants for which IF scores were available (Kahlon et al., 2021). We scaled the measured components (ROS, ET, SA, ABA, IAA and PA) in this study with function scale() and used used the binomial variable (y) which is infection outcome, of all the plants performed on three different dates. The replicate per plant and the different dates on which each experiment was performed were used as a random effect in all the models. Figures were made using the R package $\{$ ggplot 2$\}$.

\section{Validation of ET accumulation in delivering resistance in individuals from the southern coastal population}

ET validation experiments were performed on two individuals (plant 05 and plant 10) from a southern coast population, LA4107, selected based on Pearson's correlation among ET production and infection frequency. ET measurement in the leaf discs was performed as described above. ET blocking was performed by adding $5 \mu \mathrm{M}$ aminoethoxyvinyl gylcine (AVG) (Sigma) to the samples and 3 hours post-treatment ET was measured by gas chromatography. The infection phenotype upon treatment with $5 \mu \mathrm{M}$ AVG was determined using detached leaf infection assay as described in Kahlon et al. (2021): detached leaves were surface sterilized with $70 \%$ ethanol and kept upside down (adaxial side facing upwards) in 
plastic boxes containing a wet tissue bed. The leaf set for AVG treatment was kept on a wet tissue bed made with water containing AVG $(5 \mu \mathrm{M})$ and leaves were sprayed with $5 \mu \mathrm{M}$ AVG following drop inoculation with $P$. infestans isolate Pi100 (3000 sporangia/ml). The experiment was repeated on eight individual leaves per treatment. Throughout the experiment, $18-20^{\circ} \mathrm{C}$ temperature was maintained and boxes were kept in dark. The infection outcome was taken at 7 days post-inoculation.

\section{Results}

Laminarin elicits a transcriptional response overlapping with that elicited by $P$. infestans

First, we set out to confirm whether the purified glucan elicitor laminarin can elicit oomycetelike early defence responses in S. chilense. Therefore, we infected S. chilense plants of population LA3111 with $P$. infestans or treated the plants with laminarin and measured the transcriptional response after 3 hours.

As expected, infection with $P$. infestans triggered strong transcriptional responses. In total, we measured 595 differentially expressed genes (false discovery rate adjusted $p$-value<0.05) upon $P$. infestans infection (371 up-regulated and 224 down-regulated). Laminarin treatment results in 102 differentially regulated genes (31 up-regulated and 72 down-regulated) (Table S2). More than $50 \%$ of the genes that were differentially expressed after laminarin treatment were overlapping with the $P$. infestans-associated response. For the upregulated gene fraction, the overlap was $77 \%$ (Figure 1a-c). To validate our hypothesis that laminarin triggers a decomplexified defence response, we analysed the annotations of the overlapping gene lists. $35 \%$ of the overlapping genes are associated with the Biological process: Stress Response and the overlapping fraction is significantly more often annotated with the GO terms enzyme regulator activity and receptor activity (Figure 1d-e). Moreover, homologs of more than half of the overlapping genes are reported in the literature to be involved in defence responses (Table S3). We found homologs of regulators of the plant ROS response (SOLCI005830700, Peroxidase CEVI1), key regulators of defence hormone signalling like ER5 (SOLCI004643500, ET response); LOX1 (SOLCI003764800, JA signalling) or PAL3 (SOLCI000597200, SA signalling) and upregulation of Mitogen-activated protein kinases (MAPKs, SOLCI002491100). This supported that laminarin can trigger a subset of oomyceteassociated defence responses and is a suitable compound to study variation in basal defence responses in S. chilense. 

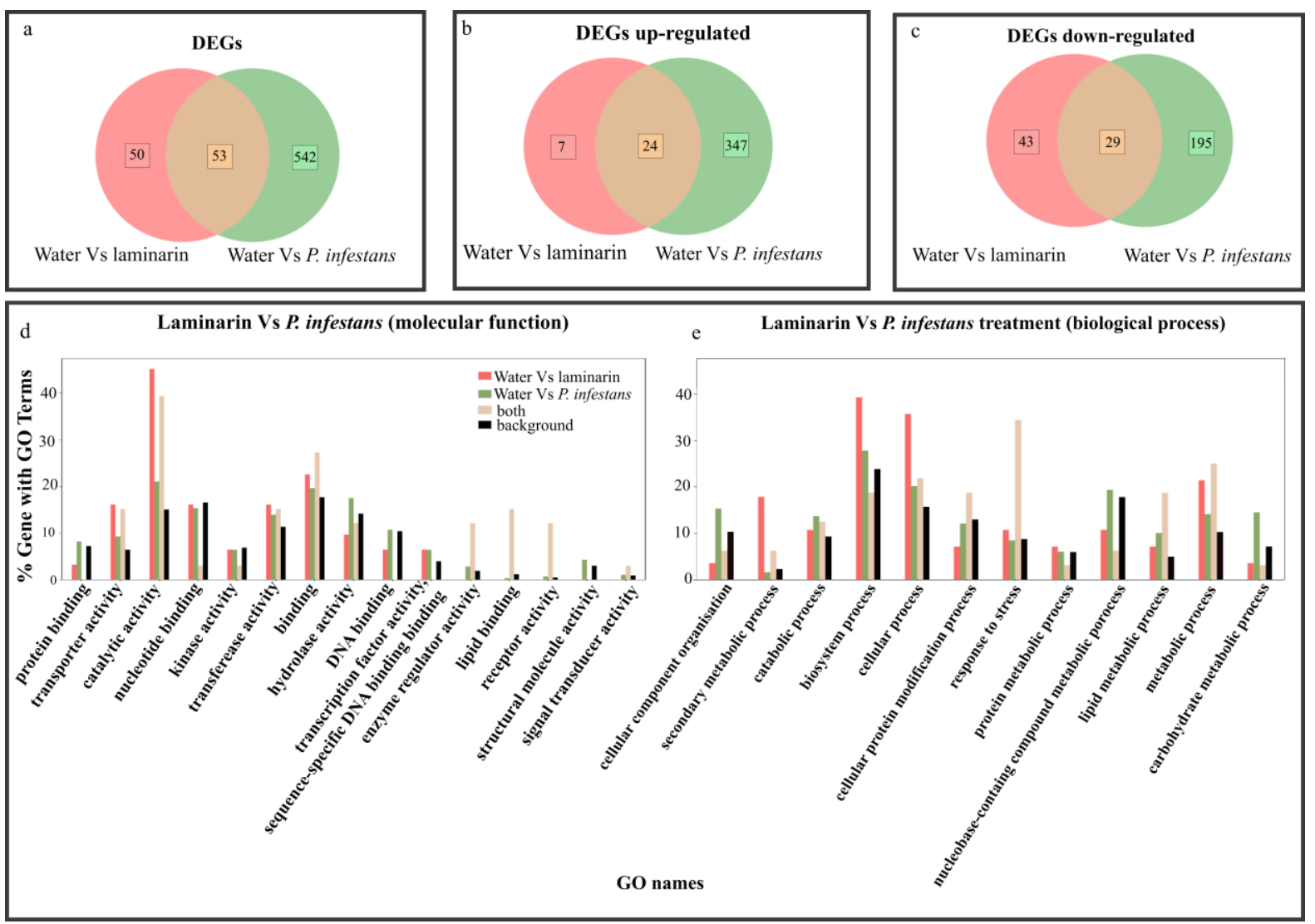

Figure 1: RNAseq analysis of the central population LA3111 (nine plants pooled per treatment) of $S$. chilense 3 hours after $P$. infestans $(3000$ sporongia/ml), laminarin $(1 \mathrm{mg} / \mathrm{ml})$ and water treatment. Differentially expressed genes (DEGs) overlap in different treatment: overall (a), up-regulated (b) and down-regulated (c), Gene Ontology (GO) analysis of RNA-seq data showing \% genes with signals for gene ontology terms for biological and molecular function for laminarin Vs P.infestans treatment $(\mathrm{d}, \mathrm{e})$.

To independently verify the involvement of laminarin-specific phytohormone-associated defence responses, we evaluated the expression of key regulators described in literature of three phytohormones, ET, SA and JA (as discussed in methods) in an S. chilense individual from a different central population: LA1963 plant 02 . We observed an up to 7.8-fold increase in expression of S. chilense ACS2 (SOLCI000989600), a key regular in the ET pathway in laminarin treated samples as compared to water-treated samples (Figure S1). Next, we looked into key regulators from the two known pathways for SA regulation. We observed that $P A L$ like transcripts (SOLCI002546900) showed up to 14-fold increase in laminarin-treated samples as compared to water-treated controls. ICS (SOLCI004470400), the key regulator of the second SA pathway was downregulated (Figure S1). For the JA pathway, we performed qPCR on the LOXD (SOLCI003768300) gene and observed an up to 10-fold increase in the laminarin treated samples (Figure S1). Thus, we confirmed differential regulation of key regulators in defenceassociated phytohormone pathways. 
bioRxiv preprint doi: https:/doi.org/10.1101/2021.06.25.449942; this version posted June 26, 2021. The copyright holder for this preprint (which was not certified by peer review) is the author/funder, who has granted bioRxiv a license to display the preprint in perpetuity. It is made available under aCC-BY 4.0 International license.

\section{ROS production in S. chilense is highly polymorphic}

ROS is an important key regulator in early immune responses, and regulators of the pathway were detected to be differentially expressed in the RNAseq (Table S3). Thus, we tested ROS production in 83 genetically distinct plants of $S$. chilense upon elicitation with laminarin. Interestingly, we found ROS production in all the plants to be reproducibly very diverse, with some plants showing high ROS production and others showing no detectable ROS production upon elicitation with laminarin (Figure 2).

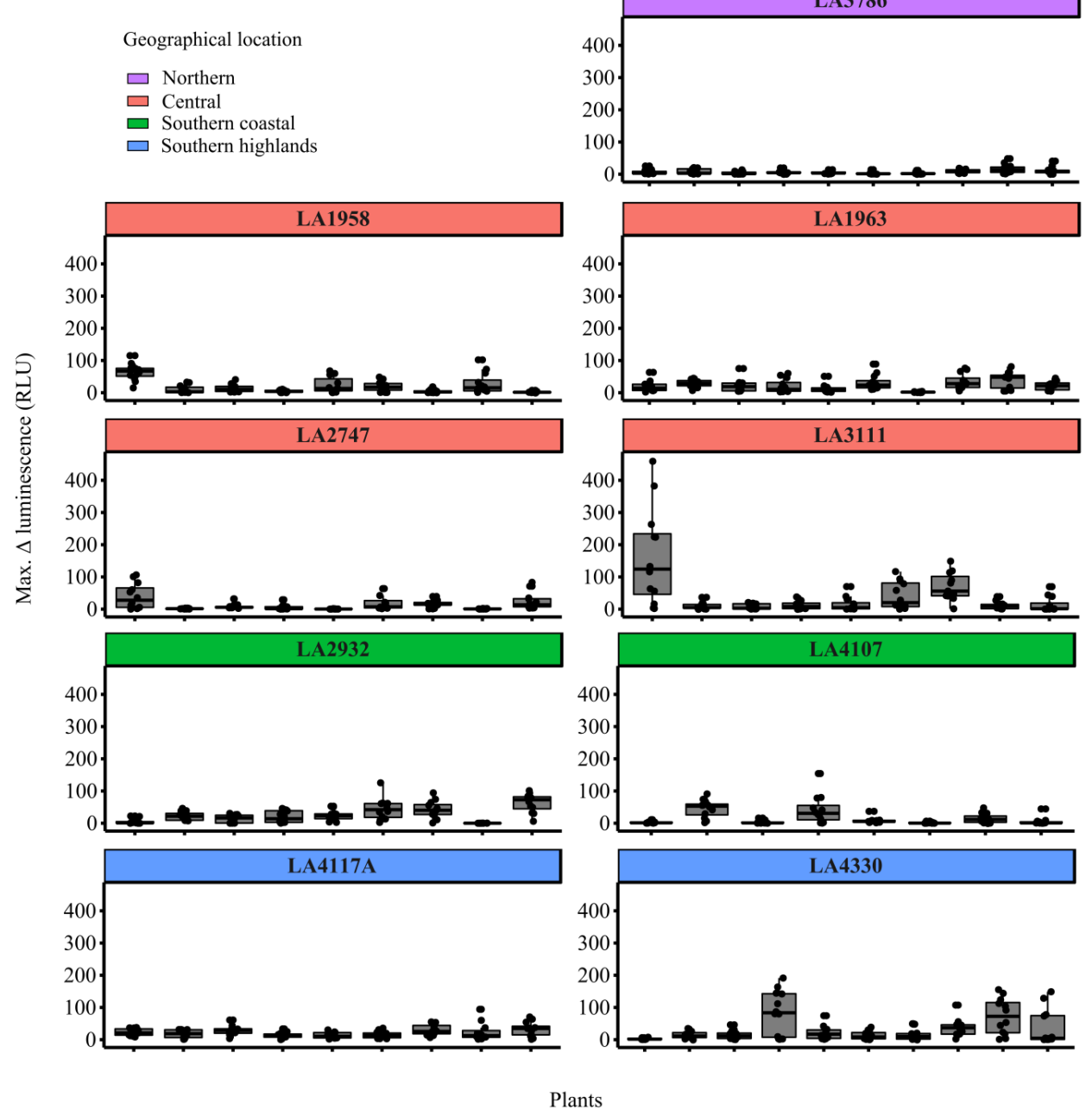

Figure 2: Maximum ROS accumulation in the leaf discs from Solanum chilense measured from 0-180 minutes upon elicitation with laminarin $(1 \mathrm{mg} / \mathrm{ml})$. Each box plot represents an individual plant per population with data from one leaf disc represented as one data point accounting up to ten to twelve leaf discs per plant. Individual measurements were performed on three different dates ( $n=3-4$ each date; $3 \times 3(4)=10(12)$ leaf discs per plant). Y-axis shows relative luminescence unit (RLU). Each panel shows different population and colors represent the geographical location of the population.

We also observed variation in the kinetics of the ROS production, with plants in some populations not showing a clear single peak, but rather a longer-lasting ROS production. This phenomenon appeared more common in the southern populations and occurs most frequently 
in population LA4117A (Figure S2). To confirm the specificity of the observed ROS production towards laminarin, we further tested ROS production after elicitation with the bacterial PAMP peptide flg22 in population LA4330 (Figure S3) and also found variable ROS production upon elicitation with flg22. Interestingly, there appears to be no apparent correlation between the strengths of flg22- and laminarin-triggered responses. Some plants showed no flg22 response and a clear laminarin response, or vice versa and some plants showed responses in similar intensity. This suggests that the observed differences are not a general effect in ROS production ability or defence signalling pathways, but rather an elicitor-specific variation.

Maximum ROS production after laminarin elicitation was significantly different between the populations (Table S4). The highest average ROS maximum was recorded in LA3111 and the lowest average in LA3786. When grouping the populations in geographical region and looking at the overall average in ROS maxima the southern highlands group had the highest ROS production and the northern group had the lowest (Figure S4a). We also found significant differences in ROS maxima in within the individual populations for 8 out of 9 populations (Table S5).

We found no correlation between the observed ROS maxima and the infection frequency observed with $P$. infestans (Kahlon et al., 2021) (Pearson's correlation coefficient of 0.09, pvalue $=0.37$, Table 1 ). This indicates that ROS production in laminarin-associated quantitative defence responses is insufficient to assess quantitative resistance against $P$. infestans in $S$. chilense.

\section{ET accumulation correlates with quantitative resistance of $S$. chilense}

To evaluate the potential effect of phytohormones in quantitative resistance observed in $S$. chilense, we first looked into ET production. Upon elicitation, with laminarin, we observed that plants showed significant differences in ET production as compared to mock-treated samples (Figure 3, Table S6 and S7). Out of 83 plants tested, we found significantly induced ET production in 39 plants upon elicitation. Plant 02 from LA1963 showed a clear ET response and so do several plants from population LA3111, confirming our results above (Table S7). Hence, differential ET-pathway gene expression in these plants appears associated with laminarin-elicited ET accumulation. 


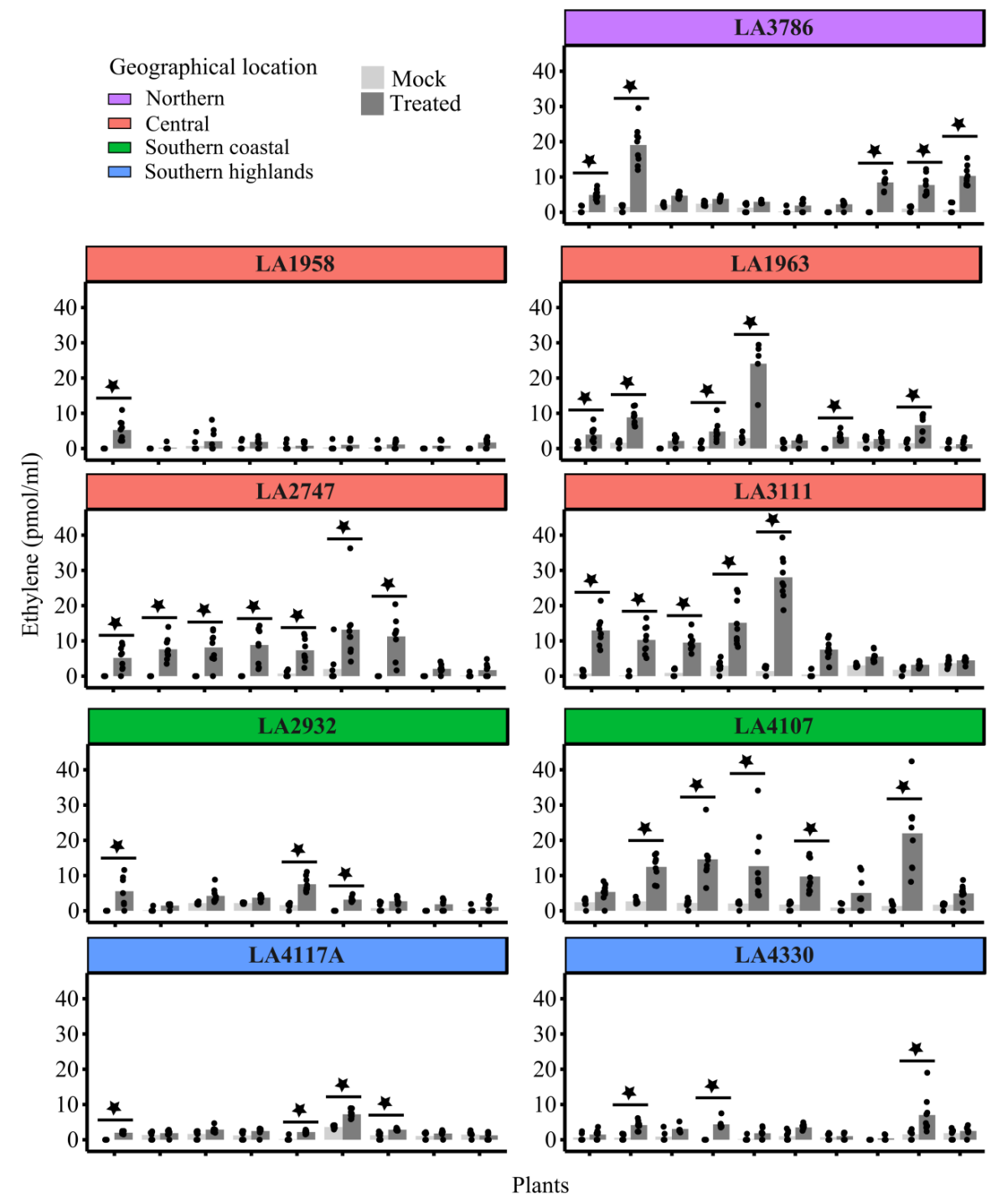

Figure 3: ET accumulation in the leaf discs from S. chilense 3 hours upon elicitation with laminarin $(1 \mathrm{mg} / \mathrm{ml})$ and mock (milliQ $\left.\mathrm{H}_{2} \mathrm{O}\right)$. Each bar pair (light grey and dark grey) represents an individual from the population where light grey is mock treated samples and dark grey is laminarin treated samples. Each bar shows mean of 7-9 data points which represent 7-9 samples measurements performed on three different dates ( $n=2-3$ samples each date), each sample contained three leaf discs. Significantly different ET accumulation in laminarin treated samples from the mock treated samples in an individual is represented with the star on the bar pair (ANOVA with post hoc Tukey tests on complete dataset). Yaxis shows ET accumulation in $\mathrm{pmol} / \mathrm{ml}$ headspace of the samples. Each panel shows different population and colors represent the geographical location of the population.

When looking at ET accumulation at the population level we find significant differences between the populations (Table S8). Contrary to ROS production, grouping the populations based on their geographical locations shows that overall average of ET accumulation was lowest in the southern highlands group. ET accumulation was at similar levels in other geographical groups (Figure S4b). When comparing ET accumulation within populations, we observed a varied number of significantly different pairwise comparisons for each population. 
As shown in Table S9, LA3786 showed the most differences between individual plants and LA2747 was the most uniform. The Pearson's correlation of infection phenotype with ET accumulation in individual plants showed a negative correlation $(-0.36, p$-value $=0.0008$; Table 1). This suggests that the laminarin-triggered ET response plays a role in defence in S. chilense against $P$. infestans or at least is indicative of quantitative resistance.

\section{High diversity in the basal level of phytohormones}

Next, we looked into the production of two important defence-related phytohormones and their derivatives, for which we detected expression of key regulators in our RNAseq data, SA and JA, as well as other phytohormones involved in stress responses: ABA, PA, DPA and IAA. We observed that most plants did not show strong differences in the level of SA (free and total) after elicitation with laminarin (Figure 4 and 5 and Table S6). Four plants form an exception: two showed a higher amount of free SA (LA3111 plant 05 and LA4330 plant 05), and two showed a lower amount of free SA (LA2932 plant 12 and LA4107 plant 12) when compared to the mock-treated samples (Figure 4). These differences did not correspond with those plants being more resistant or susceptible than other plants in the corresponding populations.

Interestingly, we measured significant differences in basal levels of free and total SA within and between populations. We found a correlation coefficient of 0.46 ( $p$-value $=1.10 \mathrm{E}-05)$ between free and total SA content (Table S10). Due to this low correlation, we treated free and total SA independently in further analyses. Basal SA levels (free and total) were significantly different between the populations (Table S11). As with ROS and ET responses, we also found significant differences within the populations for both free SA and total SA content (Table S12). There was a trend for a slight negative correlation between total SA and infection success of $P$. infestans (Pearson's correlation coefficient: -0.149 ; $p$-value $=0.069$, Table 1 ). 

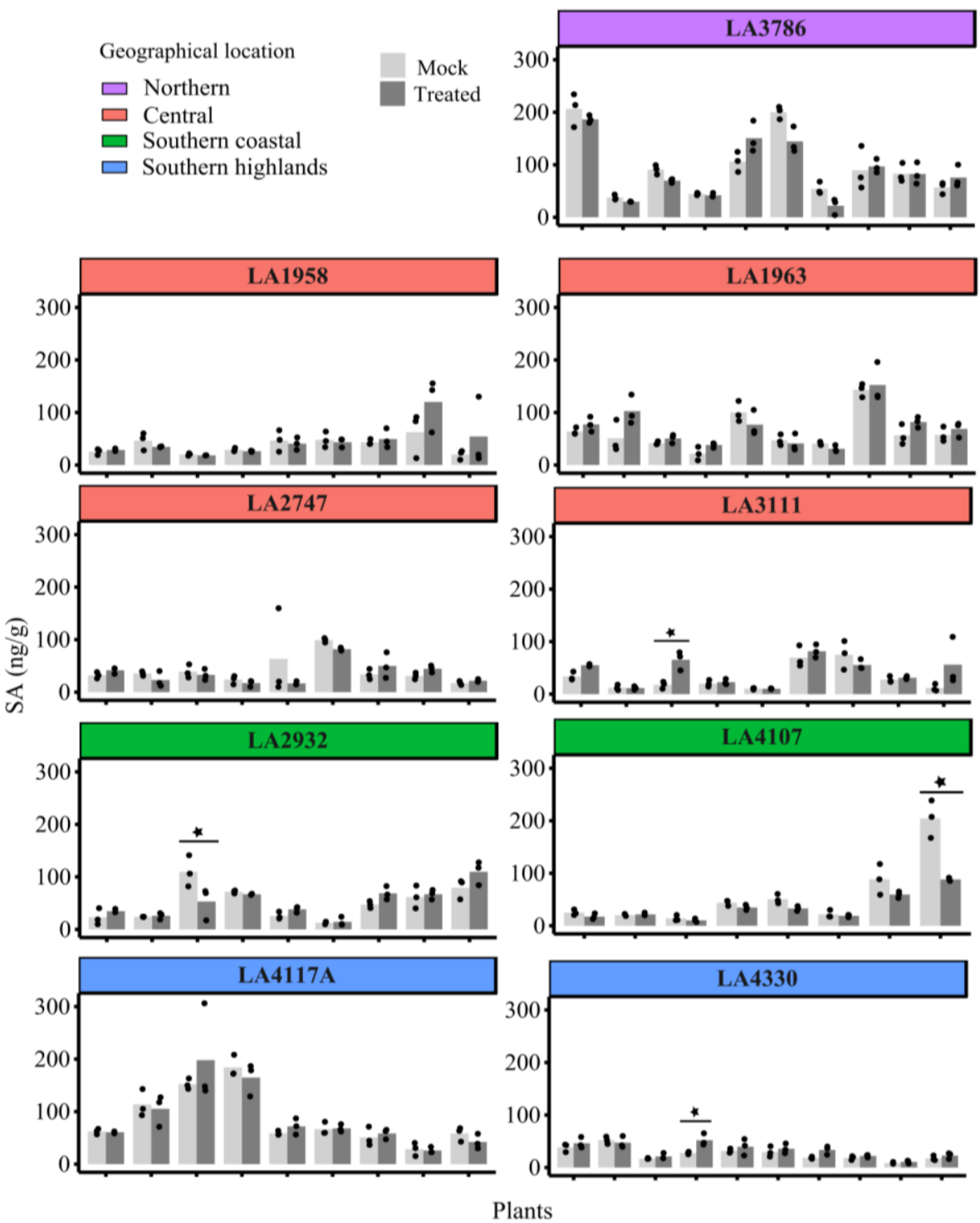

Figure 4: Free SA evaluation in the leaf discs from S. chilense 3 hours upon elicitation with laminarin $(1 \mathrm{mg} / \mathrm{ml})$ and mock (milliQ $\left.\mathrm{H}_{2} \mathrm{O}\right)$. Each bar pair (light grey and dark grey) represents a single individual from the population where light grey is mock treated samples and dark grey is laminarin treated samples from the same individual (color scheme similar to figure 2). Each bar is mean of 3 data points which comprises 3 samples measurements, each sample contained 50-100mg of fresh leaf weight obtained from the treated leaf discs (around 200 leaf discs per sample). Significantly different accumulation of free SA in laminarin treated samples from the mock treated samples in an individual is represented with the star on the bar pair. Y-axis shows SA accumulation in ng/g of the samples. Each panel shows different population and colors represent the geographical location of the population.

We did not detect JA in any of the samples tested. We measured ABA, PA, DPA and IAA, which are described to be important for biotic stress responses and pathways of several of these hormones influence each other. We did not detect DPA in our samples. We were able to detect basal levels for phytohormones ABA (free ABA, Figure S5 and total ABA, Figure S6), PA (Figure S7), and IAA (Figure S8). As expecetd, laminarin treatment did not significantly change the level of these phytohormones except for PA (Table S6). For PA we observed a 
significantly lower amount after treatments when compared to the basal level in these plants (Figure S7 and Table S13). Although, in general basal levels of PA and PA levels upon elicitation were highly correlated (Pearson's correlation coefficient of $0.74, p$-value $=2.2 \mathrm{E}-016$ ) (Table S10). We observed a higher amount of basal levels of free and total ABA in LA2932 as compared to other populations, whereas IAA was higher in LA3111 (Figure S5, S6 and S8). The levels of all these phytohormones show significant differences between and within populations (Table S14 and Table S15, respectively) in an independent manner (Table S10). By combining the data of all the tested populations based on geographic location, we found higher levels of basal PA in the southern coast and IAA was higher in the central region whereas SA (free and total) was high in the north and ABA levels were higher in northern and south coast populations (Figure S4c-h). The Pearson's correlation with infection phenotype of 83 plants with basal levels of PA showed a negative correlation $(-0.2443413, p$-value $=0.026$; Table 1) indicating that the basal level of PA plays a role in defence response. In this context, we observed no strong or significant $(p$-value $<0.05)$ correlation for SA, ABA and IAA (Table 1). 


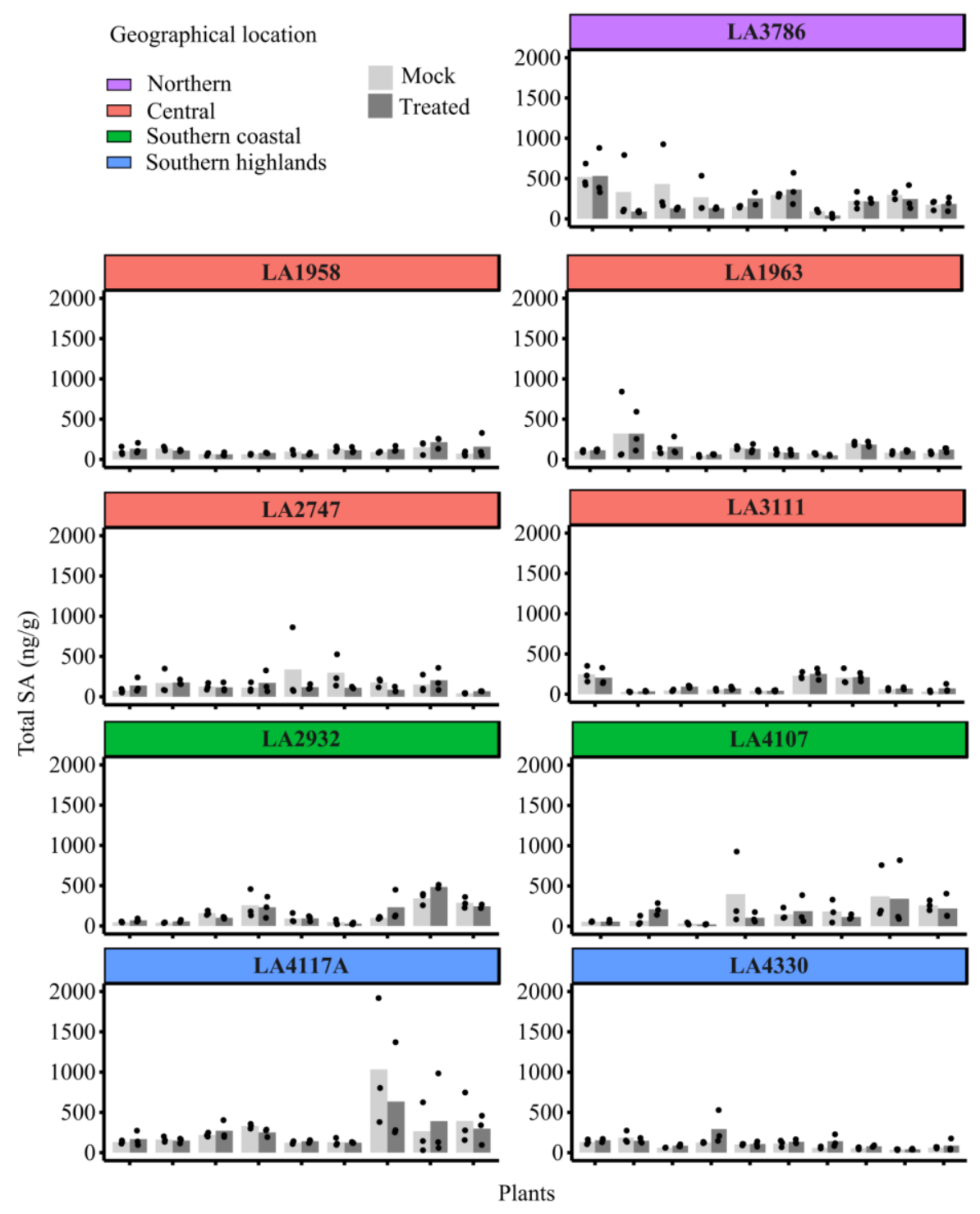

Figure 5: Total SA (free SA+SA-g) accumulation in the leaf discs from $S$. chilense 3 hours upon elicitation with laminarin $(1 \mathrm{mg} / \mathrm{ml})$ and mock (milliQ $\left.\mathrm{H}_{2} 0\right)$. Light and dark grey bar pair represents an individual from the population with and without treatment with laminarin $(1 \mathrm{mg} / \mathrm{ml})$. Y-axis shows total SA accumulation in ng/g of the samples. Color of facet represents the geographical location and each facet represents a single population.

\section{GLMMs explain resistance with an additive effect of basal and induced responses}

We observed that ET and PA correlate with the resistance phenotype when looking at them as an individual component (Table 1). 
Table 1: Pearson's correlation of measured potential immunity-related factors at basal levels and upon elicitation with laminarin $(1 \mathrm{mg} / \mathrm{ml})$ with the infection frequency (IF) of same plants upon inoculation with $P$. infestans Pi100 published in Kahlon et al. (2021b). The correlation is shown for the all the measured components. Significant correlation is highlighted in green.

\begin{tabular}{l|l|l} 
Parameter compared & $\begin{array}{l}\text { Pearson's correlation } \\
\text { coefficient }\end{array}$ & $p$-value \\
\hline IF ROS & 0.09868593 & 0.3748 \\
\hline IF $\sim$ ET & -0.3601478 & 0.0008249 \\
\hline IF Free SA (Basal) & -0.05381284 & 0.629 \\
\hline IF Total SA (Basal) & -0.1487753 & 0.06913238 \\
\hline IF Free IAA (Basal) & -0.1218008 & 0.2727 \\
\hline IF Free ABA (Basal) & -0.1215489 & 0.2737 \\
\hline IF Total ABA (Basal) & -0.1298791 & 0.2419 \\
\hline IF PA (Basal) & -0.2443413 & 0.026
\end{tabular}

To evaluate the effect of multiple components combined in driving the resistance outcome in an individual plant genotype, we generated generalised linear mixed models (GLMMs) with the IF of the tested 83 plants. We still found the effect of ET to be the highest when compared to other component's individual effects, as this produced the best fitting model based on lowest Akaike information criterion (AIC) and lowest Bayesian information criteria (BIC) among the components (Models 1.1-1.7; Table 2). Next, based on our significance tests and Pearson's correlation evaluations between measured components (Table S10) we added ROS production, ET accumulation, free and total basal SA, total ABA, basal PA and basal IAA to the model. We found the models had a better fit when the other components were used as additive effects as compared to using ET as the sole factor to model the observed infection phenotype (Table 2, Models 2.1-2.6). Combinations of one or two additional components together further improved the model fit (Models 3.1-3.5 and 4.1-4.4). The addition of more components negatively affected the model fit (Models 5.1-5.3 and 6.1-6.2) The best model based on the lowest AIC and BIC values was Model 4.3 which combined an additive effect of induced ROS and ET after laminarin elicitation as well as the effects of basal levels of total ABA and PA present in plants. The addition of IAA and SA did not contribute positively to the model's fit (Model 5.3). 
bioRxiv preprint doi: https://doi.org/10.1101/2021.06.25.449942; this version posted June 26,2021 . The copyright holder for this preprint (which was not certified by peer review) is the author/funder, who has granted bioRxiv a license to display the preprint in perpetuity. It is made available under aCC-BY 4.0 International license.

Table 2: GLMMs for evaluating the independent and additive effects of ROS, induced and basal phytohormones measured in this study on the resistance phenotype (Kahlon et al., 2021b). The lower AIC and BIC indicate a better fitting model. To construct the models we used the binomial variable (y) which is infection outcome, random effect considered in all models was batch of measurements and replicate of each plants and component absolute measurements independently were scaled using function scale(). Models highlighted in yellow are best fit within the group and green is the best fit model amongst all.

\begin{tabular}{|c|c|c|c|}
\hline GLMM & Formula & AIC & $\mathrm{BIC}$ \\
\hline Model 1.1 & $\mathrm{y} \sim \operatorname{ROS}+(1 \mid$ Batch ROS:Replicate $)$ & 3001.1 & 3011.7 \\
\hline Model 1.2 & $\mathrm{y} \sim \mathrm{ET}+(1 \mid$ Batch ET:Replicate $)$ & 2775.8 & 2786.4 \\
\hline Model 1.3 & $\mathrm{y} \sim \mathrm{SA}$ basal + (1 | Batch SA:Replicate $)$ & 3439.2 & 3449.7 \\
\hline Model 1.4 & $\mathrm{y} \sim$ Total SA basal $+(1 \mid$ Batch SA:Replicate $)$ & 3441.9 & 3452.5 \\
\hline Model 1.5 & y PA basal+ (1|Batch.SA:Replicate) & 3422.1 & 3432.6 \\
\hline Model 1.6 & y IAA basal + (1|Batch PH:Replicate $)$ & 3444.7 & 3455.2 \\
\hline Model 1.7 & y Total ABA basal + (1|Batch PH:Replicate $)$ & 3444.2 & 3454.7 \\
\hline Model 2.1 & $\begin{array}{l}\mathrm{y} \sim \mathrm{ET}+\mathrm{ROS}+(1 \mid \text { Batch ROS:Replicate:Batch } \\
\mathrm{ET})\end{array}$ & 2655 & 2669 \\
\hline Model 2.2 & $\begin{array}{l}\mathrm{y} \sim \mathrm{ET}+\mathrm{SA} \text { basal }+(1 \mid \text { Replicate:Batch ET:Batch } \\
\mathrm{PH})\end{array}$ & 2704 & 2718 \\
\hline Model 2.3 & $\begin{array}{l}\mathrm{y} \sim \text { ET + Total SA basal + (1 | Replicate: Batch } \\
\text { ET:Batch PH })\end{array}$ & 2714.8 & 2728.9 \\
\hline Model 2.4 & y ET+PA basal+(1|Replicate: Batch ET:Batch PH) & 2687.3 & 2704.9 \\
\hline Model 2.5 & $\begin{array}{l}\text { y ET+IAA basal+(1|Replicate: Batch ET:Batch } \\
\text { PH) }\end{array}$ & 2715.1 & 2729.2 \\
\hline Model 2.6 & $\begin{array}{l}\text { y ET+Total ABA basal+(1|Replicate: Batch } \\
\text { ET:Batch PH) }\end{array}$ & 2700.4 & 2714.5 \\
\hline Model 3.1 & $\begin{array}{l}\text { y ET + ROS + SA basal+ (1 | Batch } \\
\text { ROS:Replicate:Batch ET:Batch PH })\end{array}$ & 2637.4 & 2655 \\
\hline Model 3.2 & $\begin{array}{l}\text { y ET + ROS + Total SA basal+ (1 | Batch } \\
\text { ROS:Replicate:Batch ET:Batch PH) }\end{array}$ & 2637.8 & 2655.4 \\
\hline Model 3.3 & $\mathrm{y} \sim \mathrm{ET}+\mathrm{ROS}+\mathrm{PA}$ basal+ $(1 \mid$ Batch & 2626 & 2643.6 \\
\hline
\end{tabular}




\begin{tabular}{|c|c|c|c|}
\hline & ROS:Replicate:Batch ET:Batch PH) & & \\
\hline Model 3.4 & $\begin{array}{l}\text { y ET + ROS + IAA basal+ (1 | Batch } \\
\text { ROS:Replicate:Batch ET:Batch PH })\end{array}$ & 2634.6 & 2652.2 \\
\hline Model 3.5 & $\begin{array}{l}\text { y ET + ROS + Total ABA basal+ (1| Batch } \\
\text { ROS:Replicate:Batch ET:Batch PH })\end{array}$ & 2622.8 & 2640.3 \\
\hline Model 4.1 & $\begin{array}{l}\mathrm{y} \sim \mathrm{ET}+\mathrm{ROS}+\text { Total ABA basal+ Free SA basal } \\
\text { (1 | Batch ROS:Replicate:Batch ET:Batch PH) }\end{array}$ & 2624.4 & 2645.5 \\
\hline Model 4.2 & $\begin{array}{l}\mathrm{y} \sim \mathrm{ET}+\mathrm{ROS}+\text { Total ABA basal+ Total SA basal } \\
(1 \mid \text { Batch ROS:Replicate:Batch ET:Batch PH })\end{array}$ & 2624 & 2645.1 \\
\hline Model 4.3 & $\begin{array}{l}\mathrm{y} \sim \mathrm{ET}+\mathrm{ROS}+\text { Total ABA basal+ PA basal }(1 \mid \\
\text { Batch ROS:Replicate:Batch ET:Batch PH) }\end{array}$ & 2619.6 & 2640.7 \\
\hline Model 4.4 & $\begin{array}{l}\mathrm{y} \sim \mathrm{ET}+\mathrm{ROS}+\text { Total ABA basal+ IAA basal }(1 \mid \\
\text { Batch ROS:Replicate:Batch ET:Batch PH) }\end{array}$ & 2622 & 2643.1 \\
\hline $\begin{array}{l}\text { Model } \\
\text { 4.3.X1 }\end{array}$ & $\begin{array}{l}\text { y ROS + Total ABA basal+ PA basal (1 | Batch } \\
\text { ROS:Replicate:Batch PH) }\end{array}$ & 2731.2 & 2748.8 \\
\hline $\begin{array}{l}\text { Model } \\
4.3 . \mathrm{X} 2\end{array}$ & $\begin{array}{l}\text { y ET+Total ABA basal+ PA basal (1 |Batch } \\
\text { ET:Replicate:Batch PH) }\end{array}$ & 2696.8 & 2714.4 \\
\hline Model 5.1 & $\begin{array}{l}\text { y ET + ROS + Total ABA basal+ PA basal+ Free } \\
\text { SA basal (1 | Batch ROS:Replicate:Batch ET:Batch } \\
\text { PH) }\end{array}$ & 2621.6 & 2646.2 \\
\hline Model 5.2 & $\begin{array}{l}\text { y } ~ \mathrm{ET}+\mathrm{ROS}+\text { Total ABA basal+ PA basal+ Total } \\
\text { SA basal (1 | Batch ROS:Replicate:Batch ET:Batch } \\
\text { PH) }\end{array}$ & 2621.3 & 2645.9 \\
\hline Model 5.3 & $\begin{array}{l}\mathrm{y} \sim \mathrm{ET}+\mathrm{ROS}+\text { Total ABA basal+ PA basal+ IAA } \\
\text { basal (1 | Batch ROS:Replicate:Batch ET:Batch } \\
\text { PH) }\end{array}$ & 2619.6 & 2644.2 \\
\hline Model 6.1 & $\begin{array}{l}\text { y ET + ROS + Total ABA basal+ PA basal+ Free } \\
\text { SA basal + Total SA basal + IAA basal (1 | Batch } \\
\text { ROS:Replicate:Batch ET:Batch PH) }\end{array}$ & 2623.2 & 2654.8 \\
\hline Model 6.2 & $\begin{array}{l}\text { y ROS + Total ABA basal+ PA basal+ Free SA } \\
\text { basal + Total SA basal + IAA basal (1 | Batch } \\
\text { ROS:Replicate:Batch PH) }\end{array}$ & 2732.2 & 2760.3 \\
\hline
\end{tabular}

ET plays a role in defence response in southern coast tested individuals 
The GLMMs and the Pearson's correlations between the different hormone measurements and resistance outcome suggested a strong role for ET in resistance in some of the plants, followed by the effect of basal PA basal levels for which the $p$-value and the correlation co-efficient is clearly less strong (Table 1). All measured components showed geographical trends (Figure S4a-h) at basal and induced levels. This also supports that the plants' genotypes rather than the common experimental environment was the driver of metabolic differences between the plants. Thus, to confirm the possible larger effect of ET and PA on geographical groups we calculated the correlation coefficient for ET and PA for each of the geographical groups of S. chilense. We found that the effect of ET is most strongly correlated with resistance in the coastal populations, whereas PA showed the strongest correlation to resistance in the central group (Table S16).

To confirm the contribution of ET to resistance in the coastal populations, we generated a Pearson's correlation matrix between ET accumulation levels and infection frequency for 83 individuals (Figure S9) to select two plants from the matrix, one with relatively high ET production and another with relatively moderate ET production, with low and medium-high scores from the infection frequency spectrum, respectively. Both the plants were selected from southern coastal population LA4107 in which the correlation of ET and resistance was largest (Figure S9). To verify the role of ET on the resistance outcome, we used AVG, a wellestablished chemical inhibitor, to halt the ET production in the selected plants and tested the ET accumulation after laminarin treatment. AVG was successfully able to inhibit the ET production up to $100 \%$ in the plant samples (Figure 6a). After inoculation with P. infestans isolate Pi100, the plants indeed showed higher susceptibility when they were pre-treated with AVG as compared to control plants, confirming the positive role of ET in basal resistance in this population (Figure $6 b$ ). 

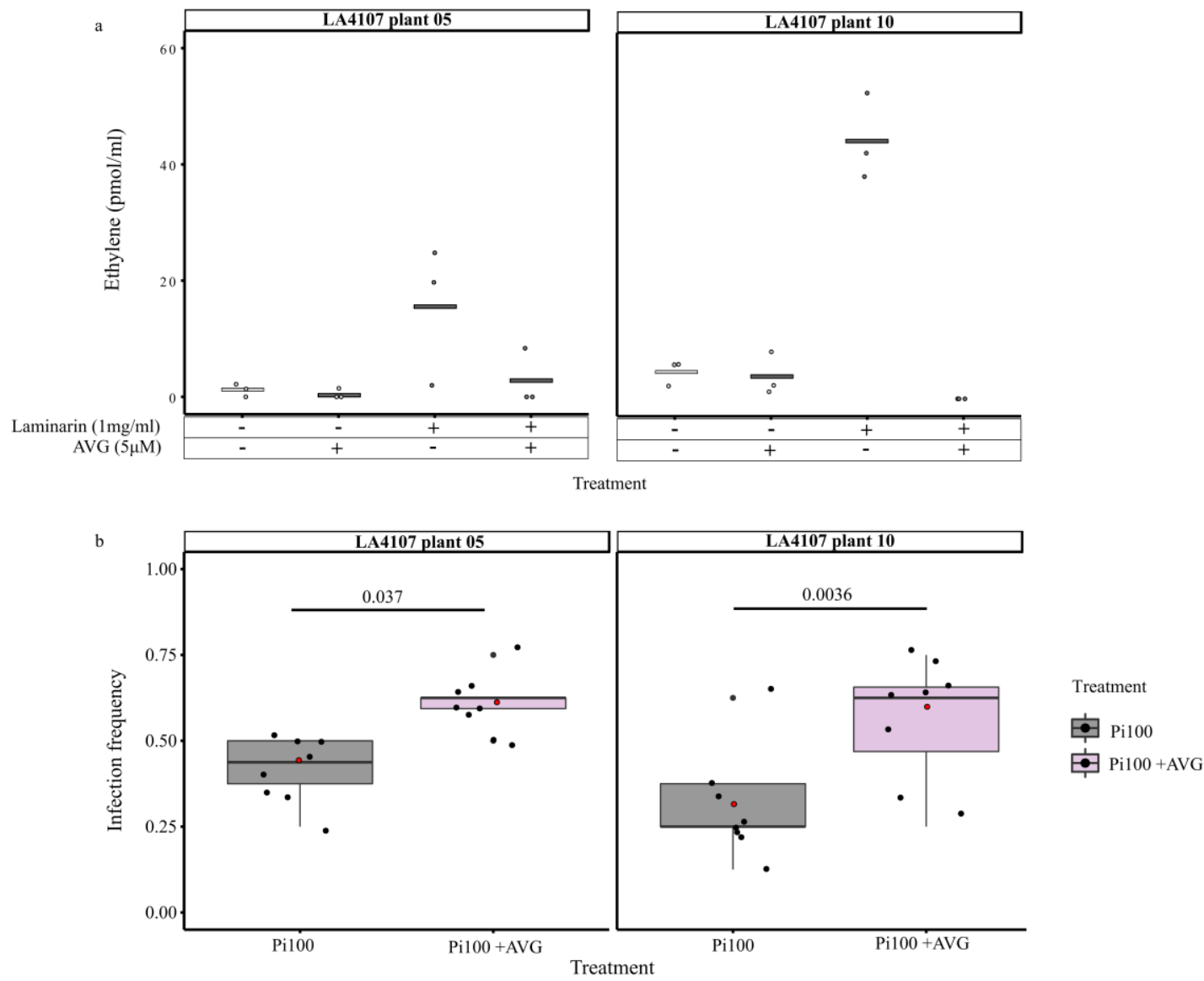

Figure 6: ET inhibition assay on LA4107 plant 05 and plant 10: ET accumulation in the the leaf discs from $S$. chilense LA4107 plant 05 and 10,3 hours upon elicitation with laminarin $(1 \mathrm{mg} / \mathrm{ml})$, AVG $(5 \mu \mathrm{M})$, laminarin $(1 \mathrm{mg} / \mathrm{ml})+\mathrm{AVG}(5 \mu \mathrm{M})$, and mock (milliQ $\left.\mathrm{H}_{2} 0\right)$. Light and dark grey crossbar pair represents plant with and without treatment with laminarin $(1 \mathrm{mg} / \mathrm{ml})$. Each crossbar is the mean of three samples measurement. Y-axis shows ET accumulation in $\mathrm{pmol} / \mathrm{ml}$ air of the samples. b) Detached leaf infection assay of LA4107 plant 05 and 10 upon drop inoculation with Phytopathora infestans Pi100 (3000 sporangia/ml) with and without AVG $(5 \mu \mathrm{M})$ treatment. Y-axis represents infection frequency which is the ratio of infected leaflets divided by inoculated leaflets. Each dot represents the ratio from one leaf, the red dot represents the mean value and the $p$-value is shown on the top of the boxplot.

\section{Discussion}

We previously used natural populations of $S$. chilense to show intraspecific variation in quantitative resistance against $P$. infestans (Kahlon et al., 2021). In this study, we evaluated several key components of basal defence in the same plants to explore molecular cues behind the previously observed phenotypic variation.

In order to reliably and reproducibly study defence components in this polymorphic plant species, and to rule out variation arising during the preparation of pathogen biological material, we used a glucan elicitor laminarin. Laminarin has been previously reported to activate basal immune responses such as ROS production, calcium influx and MAPK activation in members 
of the Solanaceae family (Meénard et al., 2004; Wanke et al., 2020). We observed significant overlaps in DEGs in S. chilense central population LA3111 upon elicitation with laminarin and infection with $P$. infestans. We found the majority of these genes to be known for involvement in defence responses. We further showed differences in transcript levels via qPCR of key regulators of defence-related phytohormones after laminarin treatment in a plant of a different central population, LA1963. This suggests that laminarin can be used as a proxy for evaluating basal immune responses activation in S. chilense.

The RNAseq on both $P$. infestans and laminarin treatment revealed regulation of homologs of several previously identified genes known in major defence pathways, like ROS production and both SA and JA signalling. These basal immunity components have been shown to be involved in $P$. infestans resistance in different Solanaceous plant species. The effect of ROS production on $P$. infestans resistance in tomato was shown to be modulated by a respiratory burst oxidase homolog (RBOH) (Cui et al., 2019). A positive effect of SA on P. infestans resistance has been reported in S. tuberosum (Halim et al., 2007). Both, SA and ET have been shown to contribute to resistance in N. benthamiana (Shibata et al., 2010), and higher levels of JA and interplay with SA were observed in resistant cultivars of Capsicum annuum (Ueeda et $a l ., 2005)$. We observed high intraspecific diversity in the above-mentioned components after elicitation with laminarin, and at basal levels. Intraspecific variation in pattern-triggered immunity (PTI) has also been reported on a transcriptional level in A. thaliana accessions, upon elicitation with the bacterial PAMP flg22 (Winkelmüller et al., 2021).

Surprisingly, we did not find a strong correlation between the amount of ROS produced in a plant after elicitation with laminarin and its resistance properties. ROS production upon biotic stress has often been considered as a hallmark of successful recognition of pathogens and the activation of defence (Torres, 2010). ROS production linked to the perception of flg22 is often taken as an indicator for resistance against bacterial Pseudomonas spp. pathogens (e.g. in A. thaliana; Smith and Hesse, 2014 and in tomato; Roberts et al., 2019). Our study shows that laminarin-triggered ROS production in S. chilense cannot be used to estimate the basal resistance against $P$. infestans. Similarly, we also found no correlation between laminarintriggered SA production or basal SA levels and P. infestans resistance. Thus, these individual defence components triggered by laminarin either show a rather limited contribution to the observed $P$. infestans resistance in the populations, or ROS and SA are not directly involved in $P$. infestans resistance in S. chilense. On the other hand, laminarin is shown to induce the ET pathway, but only sulphated laminarin ( $(3-1,3$ glucan sulfate) can induce the salicylic acid signaling pathway in N. tabacum and A. thaliana (Meénard et al. 2004). In our RNAseq 
analysis, we do see more DEGs when plants are treated with $P$. infestans as compared to laminarin. In the future, it would be interesting to evaluate the effects of sulphated laminarin and other known PAMPs from P. infestans in order to dissect the defence responses.

Our data does support that quantitative resistance observed in our plant species can be best explained by a more complex model, where resistance is dependent upon the additive effects of several components in the plants: induced ET and ROS and also basal levels of the phytohormones PA and ABA. This is in line with the hypothesis that basal defence is regulated by a complex network of interacting components from plants and pathogens (Kahlon and Stam, 2021a).

It has previously been shown that ROS production leads to SA production in a feed-forward loop in defence responses in Arabidopsis (reviewed by Herrera-Vásquez et al., 2015). We did not observe such corelation among ROS production and SA production. Additionally, a synergy between SA and ET production has also been observed in tomato resistance against the fungal pathogen Fusarium oxysporum (Di et al., 2017). Further, suppression of ABA biosynthesis and activation of ET biosynthesis upon copper ions treatment is shown to enhance resistance against $P$. infestans in potato seedlings (Liu et al., 2020b). Whereas in our system ET and ABA positively contributed to resistance observed against $P$. infestans. In our system, the strongest role in defence was found for ET. In A. thaliana, Resistance to Powdery Mildew 8 (RPW8)-mediated defence response is regulated by a ET-mediated feedback loop (Zhao et al., 2021). For Solaneceous species, the activation of defence-related genes in P. infestans resistant potato cultivars upon exogenous ET treatment has also been reported in a recent transcriptome study, by Yang et al., (2020) and laminarin triggers the expression of ETdependent defence genes in N. tabacum (Meénard et al., 2004). A positive role of ET production has been reported in relation to resistance to $C$. fulvum in tomato plants carrying corresponding resistance genes against a specific C. fulvum race (Hammond-Kosack et al., 1996). Another study showed that ET is also involved in resistance to the fungal pathogen $B$. cinerea and certain wound responses in tomatoes, with no clear role of JA or SA observed (Díaz et al., 2002). Interestingly, coordinated interaction between JA and SA has been observed to play a role in B. cinerea resistance in A. thaliana (Zhang et al., 2017).

We further showed geographical variation in basal and induced levels of each component and expect that the role of each component might differ between populations due to variation in habitats. Interestingly, the role of ET was stronger in the coastal populations and experimentally verified with ET inhibition assays in plants from coastal population LA4107. The stronger association of ET and resistance specifically in the southern coastal populations 
could be a result of specific adaptation processes in these populations. This could potentially reflect an added benefit of the development of stronger ET signalling in these populations as a result of specific habitat adaptation e.g. to deal with potential abiotic stresses, like salt stress or temperature. General temperature dependency of defence regulation and the involvement of phytohormone signalling has been shown for both cold (Wang et al., 2019) and heat stress (Huang et al., 2021). ET has been shown to be a crucial phytohormone when it comes to coping with salinity stress in plants (Riyazuddin et al., 2020). The positive effects of ET in salt tolerance have been illustrated in A. thaliana (Yang et al., 2013) and Zea mays (Freitas et al., 2018). In a study by Kashyap et al., (2020), S. chilense plants under salt stress coped better than cultivated $S$. lycopersicum due to a better anti-oxidant system. We also observed high basal levels of the phytohormone ABA in the coastal population LA2932 (Figure S5 and S6). ABA is highlighted to be an important phytohormone for abiotic stress tolerance including salinity stress (reviewed by Zhu, 2002 and $\mathrm{Ng}$ et al., 2014).

The genotype-to-phenotype linkages in systems biology are complex. Here we presented a decomplexification approach, where more components can be added to understand both the triggers (by testing different elicitors) and the outcomes (by measuring more responses). As highlighted by Marshall-Colón and Kliebenstein, (2019), such future studies should preferably be done using large-scale metabolomics and transcriptomics analyses, to determine the key regulators underlying the measured responses and to be able to appreciate the intrinsic value of the complexity of signalling networks.

In our previous studies (Stam et al., 2017; Kahlon et al., 2021) we showed no strong signs of host adaptation towards resistance to $P$. infestans, as resistance shows no clear geographical pattern of adaptation. However, our current results indicate that slightly different coping mechanisms are present in each of these populations, possibly due to specific adaptation to the niches that the plants inhabit in each region. Examples of such specific adaptations have also been observed for other host-parasite interactions. Populations of Eruca vesicaria (syns. Eruca sativa, wild rocket) from Mediterranean and desert habitats showed activation in defence responses via two different mechanisms when challenged with generalist herbivore Spodoptera littoralis. Mediterranean plants showed accumulation of glucosinolates and desert plants showed induced levels of a specific protease inhibitor (Ogran et al., 2016). Beevan et al. (1993) showed immense differences in phenotypes of two populations of Senecio vulgaris (groundsel) against Erysiphe fischeri and proposed different populations have evolved different survival strategies against the same pathogen. 
Together our data support high complexity of S. chilense's defence response to a general glucan elicitor. These responses might contribute to quantitative $P$. infestans resistance by additive or network functions. At single geographic location, certain plant hormones might play a bigger role in related mechanisms than at others. We hypothesize, that wild plants adapt to the local abiotic environment and hormones may be key to this adaptation. The corresponding defence machinery might simultaneously undergo co-adaptation to cope with biotic stress. We speculate that plants' high connectivity between abiotic and biotic signaling results in the necessity to habitat-specifically recruit different defence pathways and that the nature of the involved hormones accordingly differs in the wild. This would be determined not only by the local pathogens but also strongly by the abiotic environment.

\section{Data accessibility statement}

The transcriptome read data are deposited on NCBI SRA. The raw date from the DEG analyses and MS data as well as scripts for the DEG analyses, the analyses of the defence responses and the glmm are deposited to Zotero.

\section{Author contributions}

Conceptualization: RS, PSK, RH, CD and JB; Investigation: PSK, AF, MM, MO, MG and RHa; Data interpretation and evaluation PSK, MM, AF, MO, RS and RH; Writing and Data representation: PSK and RS. All authors reviewed and approved the manuscript.

\section{Conflicts of interests}

The authors declare that no competing interests exist.

\section{Acknowledgments}

We would like to thank Dr. Stefanie Ranf (TUM, Chair of Phytopathology), Dr. Christina Steidele (TUM, Chair of Phytopathology) and Dr. Harald Schempp (TUM, Chair of Phytopathology) for their help with setting up of ROS production assay and ET measurements assay for the wild tomato. Ethan Weiner (visiting RISE-DAAD scholar, TUM, Chair of Phytopathology) for assistance in the initial set-up of the SA and JA measurements in wild tomato, Lina Muñoz (TUM, Chair of Phytopathology) for helping with the sample preparation for phytohormones extraction, Dr. Christine Wurmser (TUM, Chair of Animal Breeding) for running the sequencing for our RNAseq experiments, Prof. Aurélien Tellier (TUM, Section of 
bioRxiv preprint doi: https:/doi.org/10.1101/2021.06.25.449942; this version posted June 26, 2021. The copyright holder for this preprint (which was not certified by peer review) is the author/funder, who has granted bioRxiv a license to display the preprint in perpetuity. It is made available under aCC-BY 4.0 International license.

Population Genetics) for sharing the S. chilense populations and Sabine Zuber, Bärbel Breulmann and Anneliese Keil for maintaining them at the TUM's plant technology center. This work was supported by a research grant to RS in frame of the collaborative research center SFB924 supported by the German Research Foundation (DFG).

\section{References:}

Audenaert, K., De Meyer, G.B., and Höfte, M.M. (2002). Abscisic acid determines basal susceptibility of tomato to Botrytis cinerea and suppresses salicylic acid-dependent signaling mechanisms. Plant Physiology 128: 491-501.

Aronson, J.M., Cooper, B.A., and Fuller, M.S. (1967). Glucans of Oomycete Cell Walls. Science 155: 332-335.

Aziz, A., Poinssot, B., Daire, X., Adrian, M., Bézier, A., Lambert, B., Joubert, J.-M., and Pugin, A. (2003). Laminarin elicits defense responses in grapevine and induces protection against Botrytis cinerea and Plasmopara viticola. Molecular Plant-Microbe Interactions 16: $1118-1128$.

Bates, D., Mächler, M., Bolker, B., and Walker, S. (2015). Fitting Linear Mixed-Effects Models Using lme4. Journal of Statistical Software 67: 1-48.

Bevan, J.R., Clarke, D.D., and Crute, I.R. (1993). Resistance to Erysiphe fischeri in two populations of Senecio vulgaris. Plant Pathology 42: 636-646.

Black, W., Mastenbroek, C., Mills, W.R., and Peterson, L.C. (1953). A proposal for an international nomenclature of races of Phytophthora infestans and of genes controlling immunity in Solanum demissum derivatives. Euphytica 2: 173-179.

Bolger, A.M., Lohse, M., and Usadel, B. (2014). Trimmomatic: a flexible trimmer for Illumina sequence data. Bioinformatics 30: 2114-2120.

Böndel, K.B., Lainer, H., Nosenko, T., Mboup, M., Tellier, A., and Stephan, W. (2015). North-South Colonization Associated with Local Adaptation of the Wild Tomato Species Solanum chilense. Molecular Biology and Evolution 32: 2932-2943.

Bradshaw, J.E., Bryan, G.J., Hackett, C.A., McLean, K., Pande, B., Stewart, H.E., and Waugh, R. (2004). Dissection and analysis of quantitative disease resistance in tetraploid potato. Euphytica 137: 13-18.

Chaudhary, A., Chen, X., Gao, J., Leśniewska, B., Hammerl, R., Dawid, C., and Schneitz, K. (2020). The Arabidopsis receptor kinase STRUBBELIG regulates the response to cellulose deficiency. PLOS Genetics 16: e1008433.

Coleman, A.D., Maroschek, J., Raasch, L., Takken, F.L.W., Ranf, S., and Hückelhoven, R. (2021). The Arabidopsis leucine-rich repeat receptor-like kinase MIK2 is a crucial component of early immune responses to a fungal-derived elicitor. New Phytologist 229: 3453-3466.

Cui, J., Jiang, N., Meng, J., Yang, G., Liu, W., Zhou, X., Ma, N., Hou, X., and Luan, Y. (2019). LncRNA33732-respiratory burst oxidase module associated with WRKY1 in tomatoPhytophthora infestans interactions. Plant Journal 97: 933-946.

Di, X., Gomila, J., and Takken, F.L.W. (2017). Involvement of salicylic acid, ethylene and jasmonic acid signalling pathways in the susceptibility of tomato to Fusarium oxysporum. 
Molecular Plant Pathology 18: 1024-1035.

Díaz, J., Have, A. ten, and Kan, J.A.L. van (2002). The role of ethylene and wound signaling in resistance of tomato to Botrytis cinerea. Plant Physiology 129: 1341-1351.

Ewing, E.E., Šimko, I., Smart, C.D., Bonierbale, M.W., Mizubuti, E.S.G., May, G.D., and Fry, W.E. (2000). Genetic mapping from field tests of qualitative and quantitative resistance to Phytophthora infestans in a population derived from Solanum tuberosum and Solanum berthaultii. Molecular Breeding 6: 25-36.

Fischer, I., Steige, K.A., Stephan, W., and Mboup, M. (2013). Sequence evolution and expression regulation of stress-responsive genes in natural populations of wild tomato. PLOS ONE 8: e78182.

Freitas, V.S., Miranda, R. de S., Costa, J.H., Oliveira, D.F. de, Paula, S. de O., Miguel, E. de C., Freire, R.S., Prisco, J.T., and Gomes-Filho, E. (2018). Ethylene triggers salt tolerance in maize genotypes by modulating polyamine catabolism enzymes associated with $\mathrm{H}_{2} \mathrm{O}_{2}$ production. Environmental and Experimental Botany 145: 75-86.

Gravino, M., Savatin, D.V., Macone, A., and De Lorenzo, G. (2015). Ethylene production in Botrytis cinerea- and oligogalacturonide-induced immunity requires calcium-dependent protein kinases. Plant Journal 84: 1073-1086.

Halim, V.A., Eschen-Lippold, L., Altmann, S., Birschwilks, M., Scheel, D., and Rosahl, S. (2007). Salicylic acid is important for basal defense of Solanum tuberosum against Phytophthora infestans. Molecular Plant-Microbe Interactions 20: 1346-1352.

Hammond-Kosack, K.E., Silverman, P., Raskin, I., and Jones, Jdg. (1996). Race-specific elicitors of Cladosporium fulvum induce changes in cell morphology and the synthesis of ethylene and salicylic acid in tomato plants carrying the corresponding $C f$ disease resistance gene. Plant Physiology 110: 1381-1394.

Hein, I., Birch, P.R.J., Danan, S., Lefebvre, V., Achieng Odeny, D., Gebhardt, C., Trognitz, F., and Bryan, G.J. (2009). Progress in mapping and cloning qualitative and quantitative resistance against Phytophthora infestans in potato and its wild relatives. Potato Research 52: $215-227$.

Heitz, T., Bergey, D.R., and Ryan, C.A. (1997). A gene encoding a chloroplast-targeted lipoxygenase in tomato leaves is transiently induced by wounding, systemin, and methyl jasmonate. Plant Physiology 114: 1085-1093.

Herrera-Vásquez, A., Salinas, P., and Holuigue, L. (2015). Salicylic acid and reactive oxygen species interplay in the transcriptional control of defense genes expression. Frontiers in Plant Science 6.

Huang, J., Zhao, X., Bürger, M., Wang, Y., and Chory, J. (2021). Two interacting ethylene response factors regulate heat stress response. The Plant Cell 33: 338-357.

Jeun, Y.C., Sigrist, J., and Buchenauer, H. (2000). Biochemical and cytological studies on mechanisms of systemically induced resistance in tomato plants against Phytophthora infestans. Journal of Phytopathology 148: 129-140.

Kahlon, P.S., Seta, S.M., Zander, G., Scheikl, D., Hückelhoven, R., Joosten, M.H.A.J., and Stam, R. (2020). Population studies of the wild tomato species Solanum chilense reveal geographically structured major gene-mediated pathogen resistance. Proceedings of the Royal Society B. 287: 20202723. 
Kahlon, P.S. and Stam, R. (2021a). Polymorphisms in plants to restrict losses to pathogens: From gene family expansions to complex network evolution. Current Opinion in Plant Biology 62: 102040.

Kahlon, P.S. and Stam, R. (2021b). Protocol for chemiluminescence based detection of ROS production in tomato. protocols.io. DOI: 10.17504/protocols.io.beeejbbe

Kahlon, P.S., Verin, M., Hückelhoven, R., and Stam, R. (2021). Quantitative resistance differences between and within natural populations of Solanum chilense against the oomycete pathogen Phytophthora infestans. Ecology and Evolution: ece3.7610.

Kashyap, S.P., Kumari, N., Mishra, P., Prasad Moharana, D., Aamir, M., Singh, B., and Prasanna, H.C. (2020). Transcriptional regulation-mediating ROS homeostasis and physiobiochemical changes in wild tomato (Solanum chilense) and cultivated tomato (Solanum lycopersicum) under high salinity. Saudi Journal of Biological Sciences 27: 1999-2009.

Kim, D., Langmead, B., and Salzberg, S.L. (2015). HISAT: a fast spliced aligner with low memory requirements. Nature Methods 12: 357-360.

Klarzynski, O., Plesse, B., Joubert, J.-M., Yvin, J.-C., Kopp, M., Kloareg, B., and Fritig, B. (2000). Linear $\beta-1,3$ Glucans are elicitors of defense responses in tobacco. Plant Physiology 124: $1027-1038$.

Kruijt, M., Kip, D.J., Joosten, M.H.A.J., Brandwagt, B.F., and de Wit, P.J.G.M. (2005). The $C f-4$ and $C f-9$ resistance genes against Cladosporium fulvum are conserved in wild tomato species. Molecular Plant-Microbe Interactions 18: 1011-1021.

Liao, Y., Smyth, G.K., and Shi, W. (2014). featureCounts: an efficient general purpose program for assigning sequence reads to genomic features. Bioinformatics 30: 923-930.

Liu, Y. et al. (2020a). Diverse Roles of the Salicylic Acid Receptors NPR1 and NPR3/NPR4 in Plant Immunity. The Plant Cell 32: 4002-4016.

Liu, H., Xue, X., Yu, Y., Xu, M., Lu, C., Meng, X., Zhang, B., Ding, X., and Chu, Z. (2020b). Copper ions suppress abscisic acid biosynthesis to enhance defence against Phytophthora infestans in potato. Molecular Plant Pathology 21: 636-651.

Livak, K.J. and Schmittgen, T.D. (2001). Analysis of relative gene expression data using realtime quantitative PCR and the 2- $\Delta \Delta \mathrm{CT}$ Method. Methods 25: 402-408.

Love, M.I., Huber, W., and Anders, S. (2014). Moderated estimation of fold change and dispersion for RNA-seq data with DESeq2. Genome Biology 15: 550.

Marshall-Colón, A. and Kliebenstein, D.J. (2019). Plant Networks as Traits and Hypotheses: Moving Beyond Description. Trends in Plant Science 24: 840-852.

Malcolmson, J.F. and Black, W. (1966). New R genes in Solanum demissum lindl. And their complementary races of Phytophthora infestans (Mont.) de bary. Euphytica 15: 199-203.

Meénard, R., Alban, S., de Ruffray, P., Jamois, F., Franz, G., Fritig, B., Yvin, J.-C., and Kauffmann, S. (2004). $\beta-1,3$ Glucan sulfate, but Not $\beta-1,3$ Glucan, induces the salicylic acid signaling pathway in Tobacco and Arabidopsis. The Plant Cell 16: 3020-3032.

Nie, J., Yin, Z., Li, Z., Wu, Y., and Huang, L. (2019). A small cysteine-rich protein from two kingdoms of microbes is recognized as a novel pathogen-associated molecular pattern. New Phytologist 222: 995-1011.

Ng, L.M., Melcher, K., Teh, B.T., and Xu, H.E. (2014). Abscisic acid perception and signaling: structural mechanisms and applications. Acta Pharmacologica Sinica 35: 567-584. 
Nosenko, T., Böndel, K.B., Kumpfmüller, G., and Stephan, W. (2016). Adaptation to low temperatures in the wild tomato species Solanum chilense. Molecular Ecology 25: 2853-2869.

Ogran, A., Landau, N., Hanin, N., Levy, M., Gafni, Y., and Barazani, O. (2016b). Intraspecific variation in defense against a generalist lepidopteran herbivore in populations of Eruca sativa (Mill.). Ecology and Evolution 6: 363-374.

Peng, J., Deng, X., Jia, S., Huang, J., Miao, X., and Huang, Y. (2004). Role of salicylic acid in tomato defense against cotton bollworm, Helicoverpa armigera Hubner. Zeitschrift für Naturforschung C 59: 856-862.

R Core Team (2020). R: The R Project for Statistical Computing.

Raduski, A.R. and Igić, B. (2021). Biosystematic studies on the status of Solanum chilense. American Journal of Botany 108: 520-537.

Ramirez-Prado, J.S., Abulfaraj, A.A., Rayapuram, N., Benhamed, M., and Hirt, H. (2018). Plant immunity: from signaling to epigenetic control of defense. Trends in Plant Science 23: 833-844.

Riyazuddin, R., Verma, R., Singh, K., Nisha, N., Keisham, M., Bhati, K.K., Kim, S.T., and Gupta, R. (2020). Ethylene: a master regulator of salinity stress tolerance in plants. Biomolecules 10: 959.

Roberts, R., Mainiero, S., Powell, A.F., Liu, A.E., Shi, K., Hind, S.R., Strickler, S.R., Collmer, A., and Martin, G.B. (2019). Natural variation for unusual host responses and flagellin-mediated immunity against Pseudomonas syringae in genetically diverse tomato accessions. New Phytologist 223: 447-461.

Sharaf, E.F. and Farrag, A.A. (2004). Induced resistance in tomato plants by IAA against Fusarium oxysporum lycopersici. Polish Journal of Microbiology 53: 111-116.

Shibata, Y., Kawakita, K., and Takemoto, D. (2010). Age-related resistance of Nicotiana benthamiana against hemibiotrophic pathogen Phytophthora infestans requires both ethyleneand salicylic acid-mediated signaling pathways. Molecular Plant-Microbe Interactions 23: 1130-1142.

Smart, C.D., Tanksley, S.D., Mayton, H., and Fry, W.E. (2007). Resistance to Phytophthora infestans in Lycopersicon pennellii. Plant Disease 91: 1045-1049.

Smith, J.M. and Heese, A. (2014). Rapid bioassay to measure early reactive oxygen species production in Arabidopsis leave tissue in response to living Pseudomonas syringae. Plant Methods 10: 6.

Soltis, N.E., Atwell, S., Shi, G., Fordyce, R., Gwinner, R., Gao, D., Shafi, A., and Kliebenstein, D.J. (2019). Interactions of tomato and Botrytis cinerea genetic diversity: parsing the contributions of host differentiation, domestication, and pathogen variation. The Plant Cell 31: 502-519.

Song, W., Ma, X., Tan, H., and Zhou, J. (2011). Abscisic acid enhances resistance to Alternaria solani in tomato seedlings. Plant Physiology and Biochemistry 49: 693-700.

Stam, R., Scheikl, D., and Tellier, A. (2017). The wild tomato species Solanum chilense shows variation in pathogen resistance between geographically distinct populations. PeerJ 5: e2910.

Stam, R., Silva-Arias, G.A., and Tellier, A. (2019a). Subsets of NLR genes show differential signatures of adaptation during colonization of new habitats. New Phytologist 224: 367-379.

Stam, R., Nosenko, T., Hörger, A.C., Stephan, W., Seidel, M., Kuhn, J.M.M., Haberer, G., 
and Tellier, A. (2019b). The de Novo reference genome and transcriptome assemblies of the wild tomato species Solanum chilense highlights birth and death of NLR genes between tomato species. G3: Genes, Genomes, Genetics 9: 3933-3941.

Steidele, C. and Stam, R. (2020). Multi-omics approach highlights differences between functional RLP classes in Arabidopsis thaliana. BioRxiv.

Takemoto, D., Shibata, Y., Ojika, M., Mizuno, Y., Imano, S., Ohtsu, M., Sato, I., Chiba, S., Kawakita, K., Rin, S., and Camagna, M. (2018). Resistance to Phytophthora infestans: exploring genes required for disease resistance in Solanaceae plants. Journal of General Plant Pathology 84: 312-320.

Tian, Z.D., Liu, J., Wang, B.L., and Xie, C.H. (2006). Screening and expression analysis of Phytophthora infestans induced genes in potato leaves with horizontal resistance. Plant Cell Reports 25: 1094-1103.

Torres, M.A. (2010). ROS in biotic interactions. Physiologia Plantarum 138: 414-429.

Torres, M.A., Jones, J.D.G., and Dangl, J.L. (2006). Reactive oxygen species signaling in response to pathogens. Plant Physiology 141: 373-378.

Tziros, G.T., Samaras, A., and Karaoglanidis, G.S. (2021). Laminarin induces defense responses and efficiently controls olive leaf spot disease in olive. Molecules 26: 1043.

Ueeda, M., Kubota, M., and Nishi, K. (2005). Contribution of jasmonic acid to resistance against Phytophthora blight in Capsicum annuum cv. SCM334. Physiological and Molecular Plant Pathology 67: 149-154.

Van der Hoorn, R.A.L., Kruijt, M., Roth, R., Brandwagt, B.F., Joosten, M.H.A.J., and Wit, P.J.G.M.D. (2001). Intragenic recombination generated two distinct $C f$ genes that mediate AVR9 recognition in the natural population of Lycopersicon pimpinellifolium. Proceedings of the National Academy of Sciences of the United States of America 98: 10493-10498.

Van de Weyer, A.-L., Monteiro, F., Furzer, O.J., Nishimura, M.T., Cevik, V., Witek, K., Jones, J.D.G., Dangl, J.L., Weigel, D., and Bemm, F. (2019). A species-wide inventory of NLR genes and alleles in Arabidopsis thaliana. Cell 178: 1260-1272.e14.

Velásquez, A.C., Oney, M., Huot, B., Xu, S., and He, S.Y. (2017). Diverse mechanisms of resistance to Pseudomonas syringae in a thousand natural accessions of Arabidopsis thaliana. New Phytologist 214: 1673-1687.

Von Kruedener, S., Schempp, H., and Elstner, E.F. (1995). Gas chromatographic differentiation between myeloperoxidase activity and fenton-type oxidants. Free Radical Biology and Medicine 19: 141-146.

Wang, L. et al. (2019). Arabidopsis $U B C 13$ differentially regulates two programmed cell death pathways in responses to pathogen and low-temperature stress. New Phytologist 221: 919-934.

Wanke, A., Rovenich, H., Schwanke, F., Velte, S., Becker, S., Hehemann, J.-H., Wawra, S., and Zuccaro, A. (2020). Plant species-specific recognition of long and short $\beta$-1,3-linked glucans is mediated by different receptor systems. The Plant Journal 102: 1142-1156.

Winkelmüller, T.M. et al. (2021). Gene expression evolution in pattern-triggered immunity within Arabidopsis thaliana and across Brassicaceae species. The Plant Cell: koab073.

Witek, K. et al. (2021). A complex resistance locus in Solanum americanum recognizes a conserved Phytophthora effector. Nature Plants 7: 198-208.

Xin, Z., Cai, X., Chen, S., Luo, Z., Bian, L., Li, Z., Ge, L., and Chen, Z. (2019). A disease 
bioRxiv preprint doi: https://doi.org/10.1101/2021.06 25.449942; this version posted June 26, 2021. The copyright holder for this preprint (which was not certified by peer review) is the author/funder, who has granted bioRxiv a license to display the preprint in perpetuity. It is made available under aCC-BY 4.0 International license.

resistance elicitor laminarin enhances tea defense against a piercing herbivore Empoasca (Matsumurasca) onukii Matsuda. Scientific Reports 9: 814.

Yang, L., Zu, Y.-G., and Tang, Z.-H. (2013). Ethylene improves Arabidopsis salt tolerance mainly via retaining $\mathrm{K}^{+}$in shoots and roots rather than decreasing tissue $\mathrm{Na}^{+}$content. Environmental and Experimental Botany 86: 60-69.

Yang, X., Chen, L., Yang, Y., Guo, X., Chen, G., Xiong, X., Dong, D., and Li, G. (2020). Transcriptome analysis reveals that exogenous ethylene activates immune and defense responses in a high late blight resistant potato genotype. Scientific Reports 10: 21294.

Zhang, W., Corwin, J.A., Copeland, D., Feusier, J., Eshbaugh, R., Chen, F., Atwell, S., and Kliebenstein, D.J. (2017). Plastic Transcriptomes Stabilize Immunity to Pathogen Diversity: The Jasmonic Acid and Salicylic Acid Networks within the Arabidopsis/ Botrytis Pathosystem. The Plant Cell 29: 2727-2752.

Zhao, Z. et al. (2021). RPW8.1 enhances the ethylene-signaling pathway to feedback-attenuate its mediated cell death and disease resistance in Arabidopsis. New Phytologist 229: 516-531.

Zhu, J.-K. (2002). Salt and drought stress signal transduction in plants. Annual Review of Plant Biology. 53: 247-273. 